\title{
Application of factorial analysis to a Brazilian metropolitan region considering the Millennium Development Goals
}

\author{
Herivelto Tiago Marcondes dos Santos ${ }^{\mathrm{a}, *}$, Rubens Alves Dias ${ }^{\mathrm{b}}$, \\ José Antônio Perrella Balestieri ${ }^{\mathrm{C}}$ \\ a Universidade Estadual Paulista, Faculdade de Engenharia de Guaratinguetá, Avenida Dr. Ariberto Pereira da Cunha, 333, Guaratinguetá, SP, Brazil \\ ${ }^{\mathrm{b}}$ Universidade Estadual Paulista, Faculdade de Engenharia de Guaratinguetá, Electrical Engineering Department, Avenida Dr. Ariberto Pereira da Cunha, 333, \\ Guaratinguetá, SP, Brazil \\ c Universidade Estadual Paulista, Faculdade de Engenharia de Guaratinguetá, Energy Department, Avenida Dr. Ariberto Pereira da Cunha, 333, \\ Guaratinguetá, SP, Brazil
}

\section{A R T I C L E I N F O}

\section{Article history:}

Received 25 November 2014

Received in revised form

10 September 2015

Accepted 17 December 2015

Available online 21 January 2016

Keywords:

Factor analysis

Millennium Development Goals

Electric energy intensity

Human dignity

\begin{abstract}
A B S T R A C T
The Millennium Development Goals (MDGs) were established by the United Nations (UN) in an attempt to mitigate environmental and economic distortions that exist worldwide. To identify opportunities to meet the aspirations of the MDGs, a few indicators (as Human Development-HDI-and the Gini indexes) were used in order to demonstrate existing inequalities among populations. This approach is also present in studies of such nature, in which electric energy intensity has been proposed as a way of overcoming the limitations of energy use assessment and its relationship with economic growth by means of the gross domestic product, seeking to impart evidence that can explain the environmental indexes more substantially. This article uses the factor analysis, a multivariate statistical analysis, to indicate the most closely correlated characteristics to the paths of human dignity and sustainable energy use. The aim of such analysis is to characterize regions and their clusters of typically urban cities to subsidize decisionmakers in the changes for the present and future populations of these cities. The chosen cities for this study are located in the Metropolitan Region of Paraiba Valley and Northern Coast (MRPV), at an economic hub represented by the cities of São Paulo and Rio de Janeiro, with historic features often associated with their economic development. However, social choices, the cultural background in the region and geographical limitations represented by the Serra da Mantiqueira and Serra do Mar have defined peculiar characteristics to the region. The contribution of using electric energy to the development of positive actions towards the MDGs when coupled with the provision of benefits to less favored populations, as well as the autonomy suggested by the results to women, a reduction of the proliferation of diseases and extreme poverty, among other aspects, were achieved with the proposed analysis.
\end{abstract}

(c) 2015 Elsevier Ltd. All rights reserved.

\section{Contents}

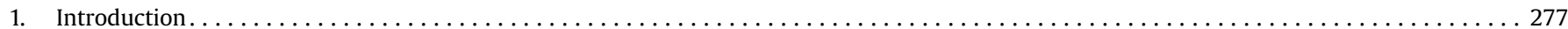

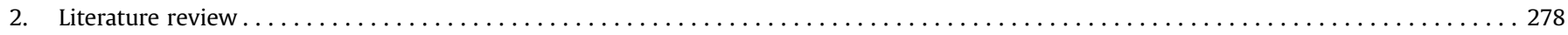

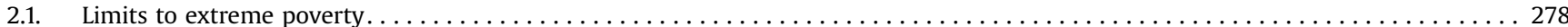

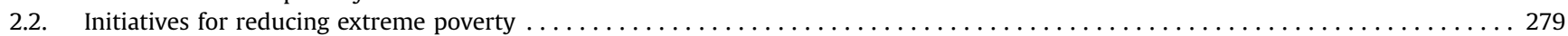

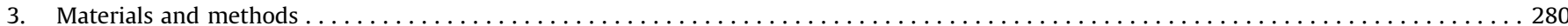

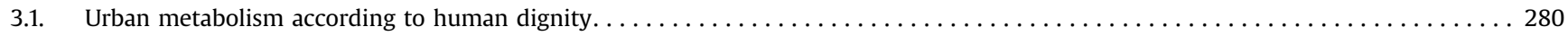

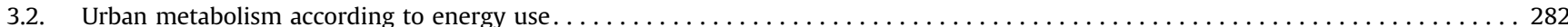

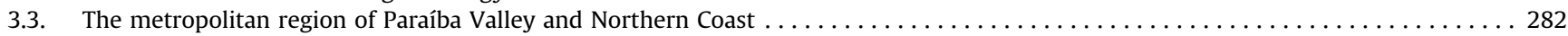

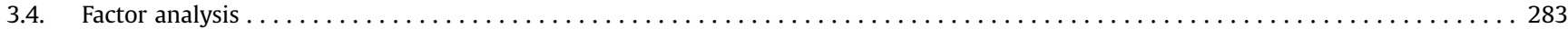

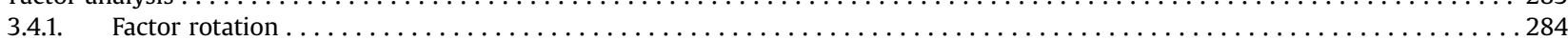

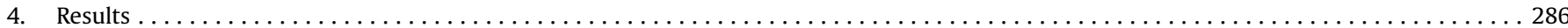

\footnotetext{
${ }^{*}$ Corresponding author.

E-mail addresses: hmarcondes@yahoo.com.br (H.T.M. dos Santos), rubdias@feg.unesp.br (R.A. Dias), perrella@feg.unesp.br (J.A.P. Balestieri).
} 


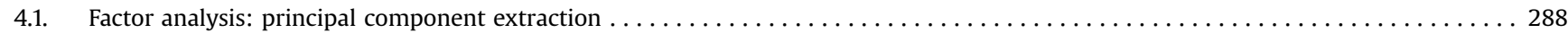

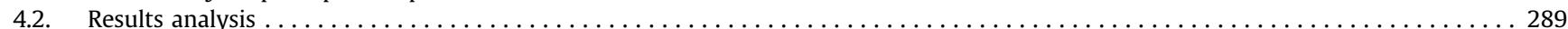

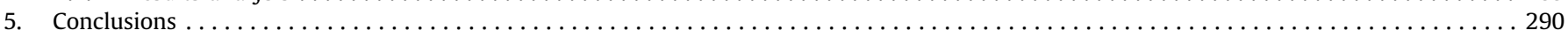

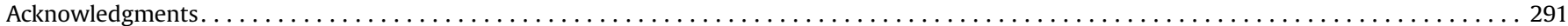

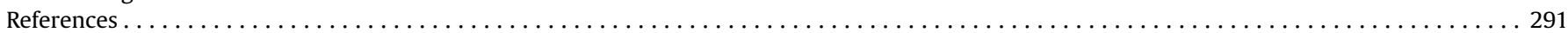

\section{Introduction}

The cities, as they are nowadays, have well-consolidated urban features due to choices made in the past, especially in terms of commerce, agriculture, culture, religion and means of transport. Since the formation of the first civilizations, the search for natural resources, such as water and minerals, allowed the populations to cluster in small spaces. This led to the formation of the first conurbations and contributed to the first constructions which defined urban features at that time, in addition to allowing commercial intentions of cities to be supported by work force and its consumers.

Rural exodus (movement known as urbanization) has created possibilities for countries seeking to balance the economic development between rural and urban areas [2,3]. However, the perception and spread of urbanization, especially in cities in Asia and South America, were not followed by investments in infrastructure for receiving and supporting basic needs, for example, in the creation of formal jobs, and regular housing and sanitation $[3,4]$.

Over the years, such urban drives have changed and generated serious environmental and economic problems associated with poor income distribution, extreme poverty, hunger, inequality between sexes and irregular land occupation, which contributed to the formation of irregular houses and slums, as well as environmental pollution (air, water and soil), deforestation and depletion of natural resources. It is not intended to state that land occupation is entirely responsible for significant changes in urban areas as these. Such changes are also due to choices resulting from the economic growth model adopted along the years and from the cultural characteristics of the cities, of which definitive models cannot be extracted. This means that one should not assign a unique effect arising from the cultural involvement of cities to changes of urban space, including traditions and typically rural ways of life.

There are also demographic elements, such as population ageing, which is increasingly growing in cities of Latin America, Caribbean, and Asia [3,5]. From an environmental viewpoint, Hogan [6] lays down that instead of the process of land occupation, social inequality is the first factor to be considered in environmental degradation and the main cause of the original changes of urban space. This can be evidenced by the lack of adequate infrastructure to urban living from the structuring of small towns.

Given this scenario, the United Nations (UN) proposed that the world's population should gather efforts towards the Millennium Development Goals (MDGs) in an attempt to mitigate the cited social and economic distortions [7]. The problems raised during the formation of cities are caused, in part, by overpopulation in some regions or by phenomenal development rates imposed to people, marked by environmental degradation, and mainly by profound social inequality [3]. Hence, public managers should make efforts so that significant changes will contribute to a reduction of extreme poverty and hunger, besides enabling the achievement of better indicators for primary education, greater equality between the sexes and greater autonomy for women. A reduction of child mortality, the improvement of maternal health, the combat of AIDS/malaria and other epidemics, reduction of waste of natural resources and protection of the biodiversity in search for environmental sustainability and global partnerships for development are also challenges to be met.
To identify opportunities to meet the aspirations of the MDGs, some indicators have been used in order to demonstrate the existing inequalities between populations, such as the Gini index, the Human Development Index (HDI) and the Theil index. The Gini and the Theil indexes have been used with the intention of presenting existing inequalities between population and income, while the HDI represents an indicator that correlates health, education and income $[8,9]$.

Through these indicators, it is also known that significant correlations between the electric energy intensity ${ }^{1}$ of the cities and their compositions can be established. For Goldemberg [10,11], neither the HDI nor the Gross Domestic Product (GDP), when considered separately, can clearly explain the social demands observed over the years. The same author claims that these social demands almost always occur in search of better living conditions, and they are not only related to the financial condition of populations, but also when they respect the traditional cultural values of populations, even if it does not represent high financial values in relation to the GDP generated in their cities, for example.

Energy use is a key element for the possibilities of imagining the fulfillment of wishes towards the MDGs. However, it is worth saying that, with caution, an increasing portion of the population of cities, lacking in better living conditions, will benefit if the power consumption, for example, does not have a mandatory dependency (necessary and sufficient) on their economic growth in the future. If the produced power units are only converted into thousands of consuming units for exclusively meeting the aspirations of the accelerated economic growth of cities, then each minimum contribution of energy consumption will not even be enough to promote the slightest social development. However, if these minimum contributions of energy consumption can generate the slightest perceptions of socio-environmental development, then individuals outside the scope of development and economic growth will be attended, without the attachment of weights from either side.

It is noticed that opportunities such as the use of renewable energy technologies (such as solar photovoltaic, wind energy and biomass energy from sugar cane, wood and urban waste) should be used, regardless of the economic growth objective, and correlated to the development of human dignity in cities. These technologies will allow future populations to be attended in their basic needs, e.g. in water heating for cooking, personal hygiene, or to meet ordinary demands as lighting and refrigeration.

Dahiya [2] reports that energy use is a key element in Asian cities, along with access to water, for better sanitation conditions and solid waste management to be achieved with the purpose of developing the MDG set, particularly regarding the reduction of extreme poverty and social inequalities in urban areas of cities. It is observed that this process has been occurring more slowly when compared to the rural areas of the Asian region. This is due to the development standards defined by the choices of decision-makers of cities, the differences between living standards required in urban and rural areas, in addition to investments allocated to rural areas due to understanding that the problem is not predominantly

\footnotetext{
${ }^{1}$ Electric energy intensity is defined as the ratio between the per capita electric energy consumption and income [kWh/capita/\$].
} 
rural and urban, which occurs because most Asian countries are composed of rural populations.

On the one hand, the socio-environmental development service must be supported with an increase in doing good deeds regarding energy use awareness, waste management (food, drinking water, mineral resources), greenhouse gases emission control, environmental protection and respect by decision-makers in public spending and investments. On the other hand, the economic growth of cities should depend solely on the sound management of its rulers in a good relationship with their professional associations and non-governmental institutions.

Arribas-Bel et al. [12] brought up new questions about the role of cities in the urbanization of regions around the world. The performance of cities in the world on aspects of broad socioeconomic interest has only met the yearnings for wealth and business, and this model is challenged to satisfy emerging social demands, such as better quality of health services, eradicating hunger and poverty in populations of cities that communicate within those models of current urban agglomeration. Thus, in the future, it is expected a social development in which cities create opportunities for improvement to meet the great energy demand to provide urgent socio-environmental improvements to populations, even if it occurs before a scenario of economic changes so-called as "mandatory", searching for an accelerated growth at all costs.

The objective of this paper is to present the opportunities offered to a Brazilian metropolitan region, in order to achieve the Millennium Development Goals, in order to better target the decision-making and the resources available to the cities. In order to do so, factor analysis, a multivariate statistical analysis tool, is used in this article for indicating which features are most closely correlated to the paths of human dignity and sustainable energy use.

Based on this, regions and their typically urban city clusters are characterized to subsidize decision-makers in the changes for the present and future populations of these cities. The cities chosen for this study are among the wealthiest cities of Brazil São Paulo and Rio de Janeiro - and are part of the metropolitan region of Paraiba Valley and Northern Coast (MRPV). This region has historic features that are often associated with its economic development. However, social choices, the cultural background in the region and geographical limitations represented by the Serra da Mantiqueira and Serra do Mar have defined some peculiar characteristics to the region.

\section{Literature review}

\subsection{Limits to extreme poverty}

The rapid pace of the growth of cities worldwide occurs with significant changes in the lifestyle of society. Currently, in most countries of Latin America and the Caribbean, a portion of the economically active population surpasses the population of children and elderly people, generating incentive opportunity for investment in more ventures that can propagate economic growth in this region $[3,13,14]$. However, a slow-paced effort made by decision-makers of these countries is seen and, by lack of control or disregard, actions that support the intentions of the MDGs are not taken. Coupled with a type of demand that is not present in every city, as the need for accelerated economic growth, there are persistent social inequalities, extreme poverty and hunger.

Currently, in order to achieve the MDGs, aimed at combating extreme poverty and hunger, it is used the standard of US\$ 1.25 a day as the income of individuals who live below the extreme poverty line [15]. According to World Bank; Pritchett and Kenny

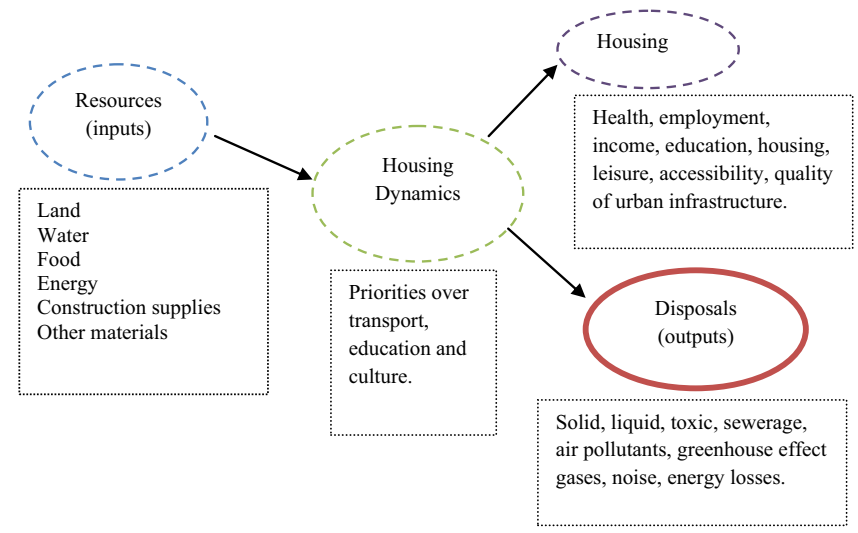

Fig. 1. Extended urban metabolism model. Source: Ref. [22].

$[16,17]$, the goal of reducing extreme poverty requires efforts from different areas of the governments of cities, such as the economy, health and education sectors. The goal of reducing extreme poverty is aimed to be achieved by the year 2015 for half the percentage of the population in this condition in 1990, when $43 \%$ of the world population lived with up to US\$ 1.25 per capita a day. In fact, presenting a per capita income of US \$1.25 a day does not mean, in countries such as Brazil, not living in extreme poverty.

For illustrative purposes, a typical Brazilian family, with four people and which receives a monthly minimum wage of $R \$$ 724.00 (US\$ 301.70) in September 2014, presents a monthly per capita income of R\$181.00 (US\$ 75.42), which is equivalent to a per capita daily income of $\mathrm{R} \$ 6.03$ (US\$ 2.51). Thus, from the point of view of the established standard, there is a capacity above the poverty line for typical Brazilian families. However, $44.70 \%$ of this value are intended to a basic food supply parcel, i.e. the individual is left with R $\$ 3.33$ (US\$ 1.39) to defray expenses with transport, clothing, housing and hygiene. It is worth pointing out that the collective public transport in Brazil represents approximately $15.90 \%$ of the monthly income of individuals, i.e. $R$ \$ 3.84 (US\$ 1.60) per capita day. A studio flat represents approximately $29.20 \%$ of their monthly salary, i.e. around $\mathrm{R} \$$ 211.00 (US\$ 87.92) per month (US\$2.93 per capita day); education and health-related aspects were considered as being offered by the public services of the cities $[18,19]$. Thus, it is assumed that combating extreme poverty based on efforts to a financial limit of US\$ 1.25 per capita/day proves to be an unrealistic and inadequate goal towards the demands for human dignity and the elimination of social inequalities that exist in cities worldwide.

To characterize the inequalities between countries, Deichmann [20] proposes that the economic, social and environmental dimensions should be divided into competence sectors of society nowadays. As an example, in economics, consumption and income are associated so that the per capita income and extreme poverty indicators generate consequences as problems of housing and production of goods. As social aspects, nutrition, use of water, basic hygiene, garbage collection and sanitation services, energy, family planning, health and education are considered. In this case, some results are associated with levels of illiteracy, infant mortality, and diseases caused by bad water use. Finally, the environmental aspects are related to the fact there is a favorable space that can generate opportunities such as access to land, leasing, credits to agriculture-related markets; as well as agricultural productivity and food safety measures.

Deichmann [20] also suggests that economic aspects themselves should not explain social inequalities. Thus, indicators such as water access, electricity, basic health, ownership, illiteracy rates, 


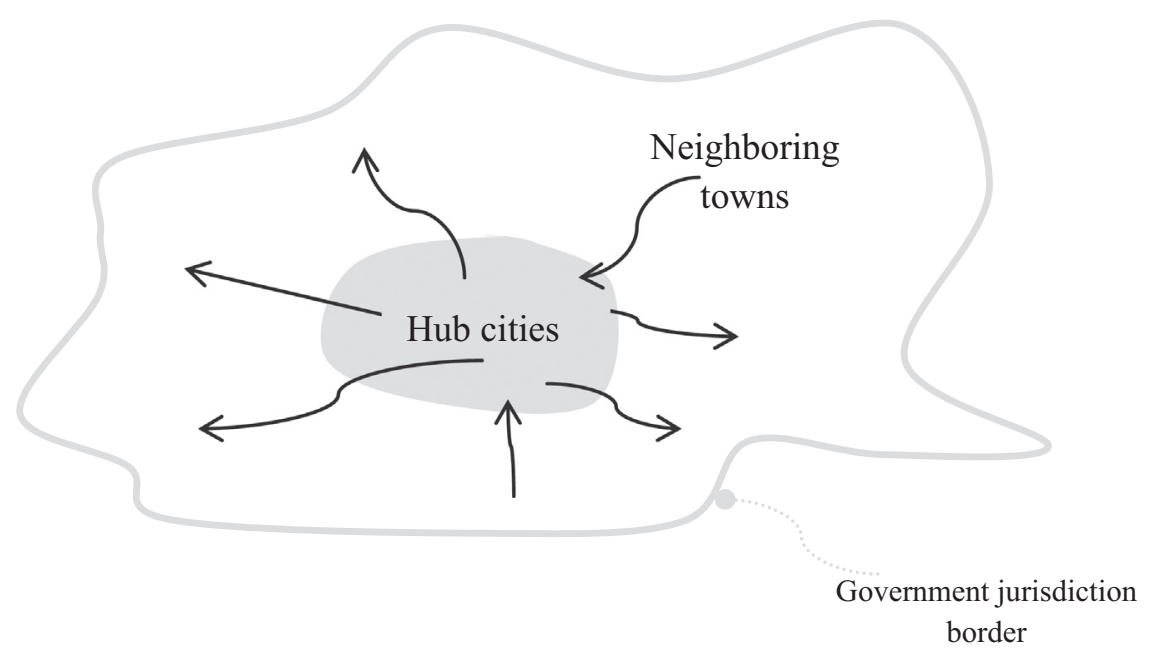

Fig. 2. Resources flow model between hub cities and their neighboring towns.

credits and leasing can better represent the advances with which cities must reduce the indicators of extreme poverty and hunger.

Wolman [21] suggests a model of urban metabolism, which can be compared to materials flow comprising the characterization of resources (food, fuel, clothing, consumer durables, construction supplies and power), its processing and even materials disposal (whether they are reusable or not), towards an incomplete cycle until they are favorably disposed of without posing hazards to human health or the environment. It is noted, in models as such, the existence of priorities that are usually understood by decision-makers of cities, though they are not always taken. Newman [22] proposes the application of an extended urban metabolism model (Fig. 1) to a cyclic relationship among resources, priorities, and living conditions in pursuit of human dignity and waste. Newman [22] includes in the model proposed by Wolman [21] the management of elements such as health, employment, income, education, housing, leisure, accessibility, and quality of urban infrastructure as housing elements, and the non-harnessed share of exploited resources.

The model translated by Wolman [21] has been generated from the transition of feudal life to capitalism, stimulating "a growing need for urban regeneration" by the production of food for supplying small communities to production on a larger scale to meet not only the demand, but also the economic interests of cities. For Deàk [23], changes of trading models and food for producing and selling the surplus in "urban" areas of cities has partly contributed to the choices made by current cities. Thus, the desire, in the course of time, for a greater production that would meet the growing demand for goods, food and land, gave rise to urban agglomeration models with increasing demands of basic condition of life and energy.

For Milder [24], the relationship among the layout of a city, its urban form and environmental performance are controversial, from which each peer relationship has its particularity to evidence the urban feature of cities; e.g., if the layout is characterized by high population density, then this suggests a need for greater connection between social and economic demands. Thus, from the population density of cities, whether it is high or low, to the distinction between residential, commercial, industrial and rural areas, regions are characterized without established boundaries of vicinities and generate commercial and social interdependencies between the borders that surround them. In addition, urban space is exposed to disorderly land occupation, if towns do not have an interest in urban planning, combined with a high level of social inequality.

\subsection{Initiatives for reducing extreme poverty}

As pointed out by Modi et al. [25], even though MDG objectives do not refer explicitly to energy, improved energy services are necessary for meeting all the Goals. The same report states that achieving all the MDGs will require greater energy inputs and access to energy services, and several key recommendations of interventions are then highlighted to national governments, from which the 8th is of great significance for the present analysis: "develop energy infrastructure and institutions that directly benefit women and the poor".

Parajuli [26] developed an analysis of the business as usual situation of energy development in Mid/Far west region of Nepal to provide an overview on energy poverty situation and to identify measures required to reduce the poverty by $50 \%$ by 2015 / 2016. For such analysis, energy poverty has been defined as the absence of sufficient choice in accessing adequate, affordable, reliable, quality, safe and environmentally benign energy services to support economic and human development. A similar analysis was developed by Bhide and Monroy [27] for stating the problems faced in India in terms of energy consumption, mainly electricity due to its capacity of providing lighting, which permits, among others, the usage of household appliances and the extension of the number of working hours to enable studying and learning beyond daylight.

Although not extensively described for Brazilian conditions, MDGs was discussed in terms of the relationship between electrification and poverty by Coelho and Goldemberg [28]. The introduction of liquid petroleum gas 70 years ago all over Brazil as a cooking fuel that replaced the use of fuel wood in rural areas was an important governmental action. The recent governmental program Luz para Todos (Light for All), which extended the electric grid to around 10 million people, is discussed by the authors to show how the country is working to solve difficulties related to energy access.

Martchamadol and Kumar [29] used historical time series of several energy indicators, as well as economic, environmental and social data to develop an aggregated energy security performance indicator (AESPI). For that, the authors used principal component analysis (PCA) based on the Varimax orthogonal rotation. The proposed indicator is suggested for studying how policies could 


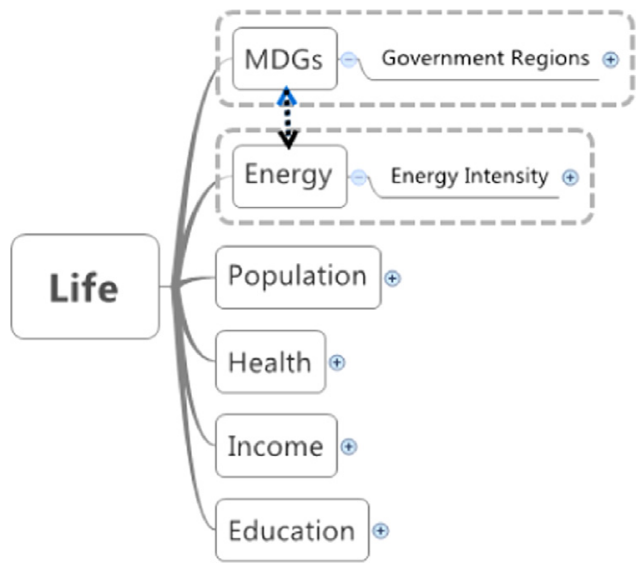

Fig. 3. Life dimension.

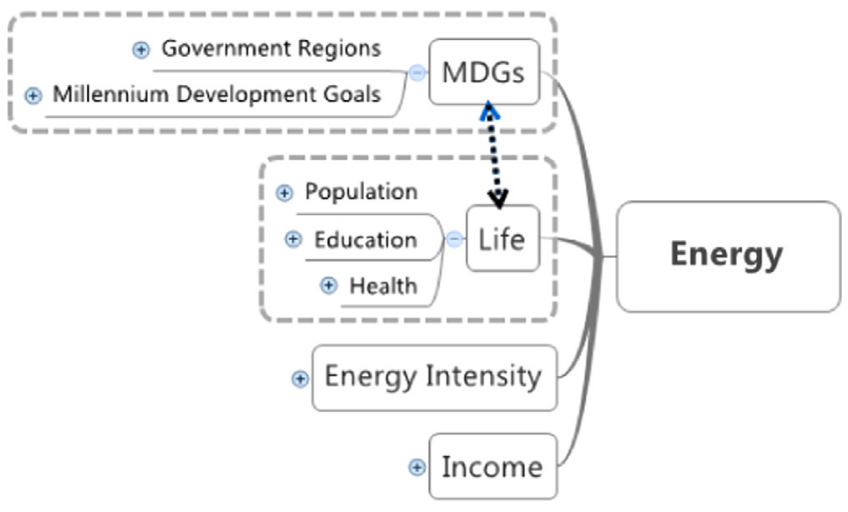

Fig. 4. Energy dimension.

help improve the country's overall energy security performance and is supposed to be a benchmark for further improvement.

\section{Materials and methods}

Relatively to the urban metabolism, the present work adopts two kinds of approach. The first one is about the possibilities of human dignity (life) and the second one is on energy use (energy intensity). In both cases, the flow of materials, technologies and disposals will occur either in the case of human dignity, or in the case of energy use.

For these approaches, a resource flow model was used among hub cities and their neighboring towns of which, the largest urban agglomerations that present the highest values of GDP are called hub cities, and the other ones are called neighboring towns. The latter are cities with greater economic dependence on the former (Fig. 2). As aforementioned, the sectors of the economy that prevails in hub cities have a certain degree of influence on the economies of neighboring cities, with a greater participation of the service sector.

The resource flow model presented in Fig. 2 comes from the idea that hub cities offer the use of resources to their neighboring towns, such as better healthcare services, education, transportation, infrastructure, formal employment, in addition to avoiding environmental pollution (air, water and soil). In contrast, neighboring cities provide manpower for the economy sectors of hub cities, better air quality, water and soil, as well as a perception of quality of life (immeasurable), associated with socio-environmental aspects faced by hub cities with problems that got out of hand in town planning and their bordering regions.

The boundaries of the centralized government region by the hub city are defined by the jurisdiction of the government area, which also features a resource flow that is similar to what occurs between cities. This means that between neighboring governments areas there are also environmental differences belonging to the scope of town planning, which are defined as priority elements.

The idea of resources flow defines hubs cities as those that have structures such as urban transport services, greater use of energy, industries. Similarly, the urban space of neighboring towns serves as social or commercial information networks that offers spaces in the land to allow the expansion of hub cities, as well as define government areas. This represents a boundless region of predefined vicinities that lead to a generalization of the model for borders of government areas that are centralized by the hub cities.

\subsection{Urban metabolism according to human dignity}

Based on the aspects of cities' metabolism on human dignity, it is suggested an intense effort toward quality of life. It is believed that quality of life will be obtained if the elements water, earth, food and energy are met at their minimum limits.

\footnotetext{
"Meeting minimum limits" is understood as the ability to create possibilities for distribution of land for dignified housing, being them away from areas of risk and with adequate basic infrastructure (very different from slums), households with access to drinking water which can also be used for cooking, as well as health care services (sanitation and garbage collection). In addition, they should allow access to drinking water to improve health conditions in order to avoid the spread of diseases, which can also allow a higher life expectancy for women and their children at birth. Regarding energy use, meeting minimum limits means satisfactorily ensuring demands for cooling and cooking aliments, as well as regular lighting that helps in guaranteeing life quality and safety of environments. In other words, meeting the minimum limits is to allow human dignity to be granted minimally, and establishing appropriate means of reaching the MDGs. Human dignity is the main aim of life dimension
} 


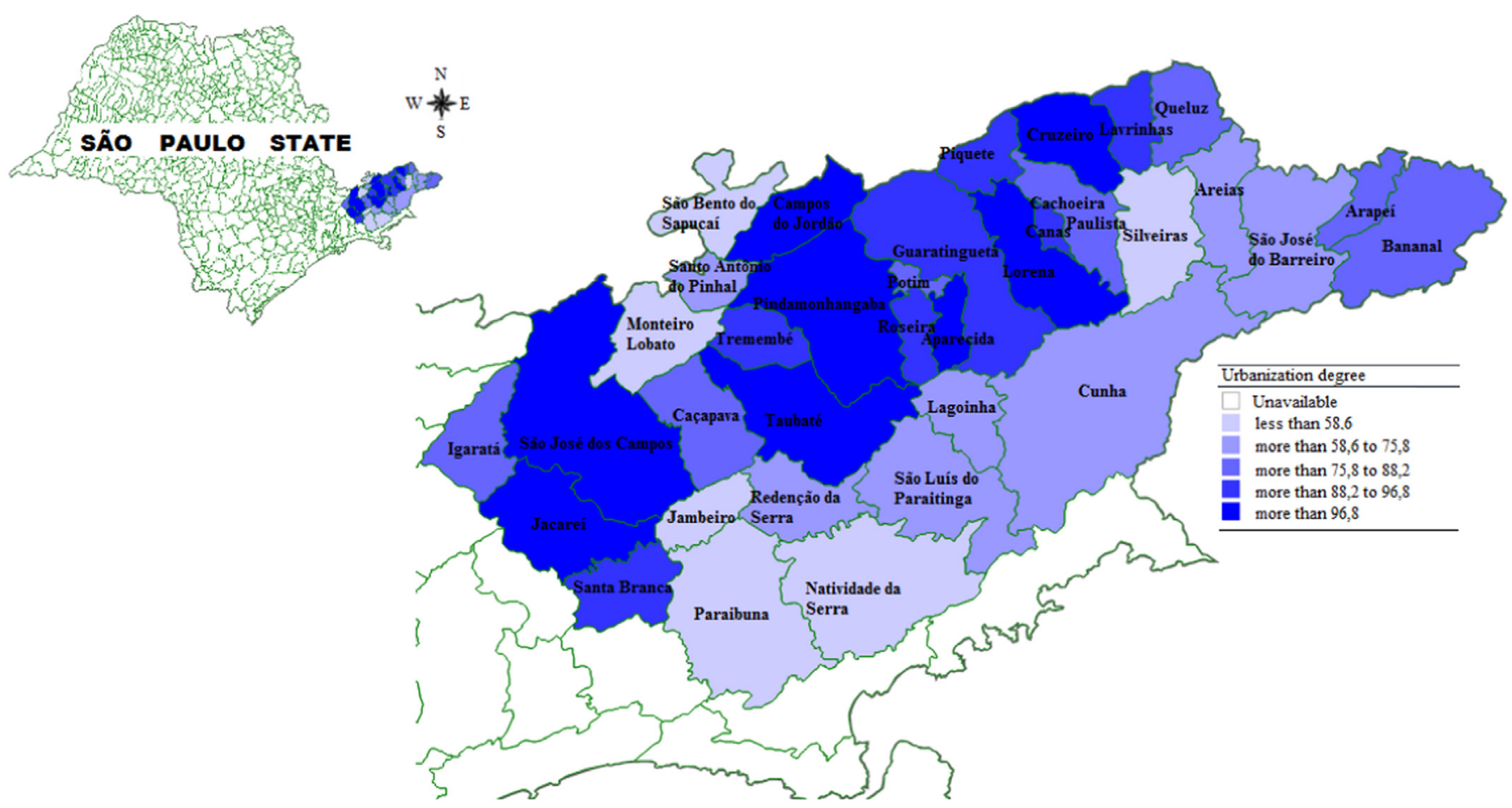

Fig. 5. Urbanization degree of cities of the government areas in the MRPV - 2014.

Source: Ref. [32].

Table 1

MRPV Government Regions - hub cities and their neighboring towns.

Source: [32]

\begin{tabular}{|c|c|}
\hline Government regions - hub cities & Neighboring towns \\
\hline GRC - Cruzeiro & Arapeí, Areias, Bananal, Lavrinhas, Queluz, São José do Barreiro and Silveiras \\
\hline GRG - Guaratinguetá & Aparecida, Cachoeira Paulista, Canas, Cunha, Lorena, Piquete, Potim and Roseira \\
\hline GRTAU - Taubaté & $\begin{array}{l}\text { Campos do Jordão, Lagoinha, Natividade da Serra, Pindamonhangaba, Redenção da Serra, São Bento do Sapucaí, São Luís do Para- } \\
\text { itinga, Santo Antônio do Pinhal and Tremembé }\end{array}$ \\
\hline GRSJC - São José dos Campos & Caçapava, Igaratá, Jacareí, Jambeiro, Monteiro Lobato, Paraibuna and Santa Branca \\
\hline
\end{tabular}

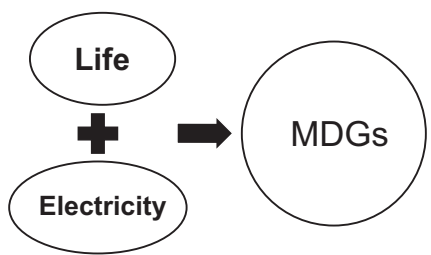

Fig. 6. Human dignity (life) and energy use (electricity) in pursuit of the MDGs.

Human dignity is the main aim of life dimension (see Fig. 3) that is proposed in this article. The choices presented in Fig. 3 (the same applies to Fig. 4) are due to the explanations given by their relationships with the MDGs existing among them, and are almost always treated individually, which justifies the study of possible correlations of these pillars in achieving human dignity.

Life dimension is correlated with the MDGs by the use of the energy sectors (industrial, commerce and public services, residential and rural) through the electric energy intensity of cities, as well as with population aspects (demographic density of urban or rural agglomerations, regular care for women, children and the elderly, HDI). Health (infant mortality, sanitation, drinking water supply, health care of women and their children, tackling diseases spread), income (GDP, social vulnerability, women's income and limits of extreme poverty), and education (degree of illiteracy, school progression) are also taken into account. If, for example, these correlations handle the use of electricity of cities associated with the MDGs aimed to support women and their children, it is observed the social aspects characterized by irregular housing, devoid of proper sanitation, low income of women as providers of their families, poor health, and high socioeconomic inequalities.

The metabolism of cities depends on the pace of economic growth chosen by nations towards the rapid growth of increasingly populous urban agglomerations, with increasing basic demands as housing, transport, health and education. Nevertheless, there are urban cities in the same manner - with typically urban social behavior and business economic features - that abdicate economic accelerated growth and keep, due to customs and culture, a growth rate aimed at social and environmental welfare.

Growth rate aimed at social and environmental welfare is understood when such growth is closer to maintenance than has not been transformed by the interference of vicinities that made choices aimed at an economic growth. The cities that have chosen to only meet the expectations of accelerated economic growth show an inability of planning to meet environmental demands. Similarly, cities that have produced and followed, from the industrial revolutions of the past centuries, unbridled economic growth models, were not able to create new mechanisms of 
Table 2

Public information database.

\begin{tabular}{ll}
\hline Database & Institution \\
\hline Federal Sphere & - IBGE -The Brazilian Institute of geography and statistics [33]; DATASUS (Department of Informatics of SUS); MCT (Ministry of Science and \\
& Technology), ANP(National Petroleum Agency), ANEEL(National Electric Energy Agency), MME (Ministry of Mines and Energy) [5,34-40]; \\
& IPEA-DATA (Institute of applied economics research) [18] \\
$\begin{array}{l}\text { State Sphere (São } \\
\text { Paulo) }\end{array}$ & - SEADE - Foundation State's System of Database Analysis [32] \\
$\begin{array}{ll}\text { International Sphere } \\
\text { - PNUD (United Nations Development Program), UNIFEM (United Nations Development Fund for women), FOA (United Nations for Food and } \\
\text { Agriculture Organization) [6,14,34,35,41] } \\
\text { - The World Bank [9,16,20] }\end{array}$ \\
\hline
\end{tabular}

adjustment of their current choices to ensure a decent future for their populations.

Which is the economic growth or social and environmental welfare path to be followed? By satisfactorily answering this question, a joint choice between two goals is still far from the reality of cities. As discussed for the MRPV in Section 3.3, the neighboring towns are able to adapt to socioeconomic changes suggested by the models adopted by the hub cities in pursuit of economic growth, characterized by a strong industrialization of the metallurgical, aviation and automobile sectors. In contrast, hub cities seek to be correlated to neighboring towns to meet some of their social demands, as tackling extreme poverty and hunger. To do this, the urban metabolism model, in line with human dignity, is served on the proposition of jobs and income generation, which is corroborated with the support of neighboring towns in their economies towards the commerce and services sectors.

\subsection{Urban metabolism according to energy use}

The metabolism of cities focused on energy use seeks to evaluate the variables that more significantly contribute to the achievement of the MDGs. Aligned with an energy planning which is adequate to the size of each city, ${ }^{2}$ the aim is to understand what leads to meeting energy demands. Energy demands that must go beyond the exclusive use of technology to understanding how these demands have been prioritized, whether they should attend something or someone. The use of energy is then justified as a key element in the promotion of service to the MDGs through a direct relation to the elements of urban life, as the condition of life of the population in their urban agglomerations, education and health, in addition to income and electric energy intensity, as it is exposed in Fig. 4.

The understanding of these two dimensions - life (Fig. 3) and energy (Fig. 4) - must go through the borders of energy, income, education and health issues towards the MDGs, in order to allow decision-makers of cities to prioritize their investments rationally through balanced public policies between meeting cities yearnings for basic living conditions, economic growth and environmental protection.

Electric energy intensity has often been used with the intention of overcoming the limitations of energy use assessment and its relationship with economic growth through the GDP, but it is also sought evidence that can explain the environmental indexes more consistently. Charpentier [30] demonstrates the distinctions existing among developed, developing and underdeveloped countries through the comparison of their GDP and per capita energy consumption. Goldemberg $[10,11]$ not only goes beyond the energy use assessment, but also defends the treatment of indicators, as the HDI, in order to seek explanations for the social

\footnotetext{
${ }^{2}$ The size of the city will be characterized by a hub city and its vicinities, from which it is extracted the influence and economic interdependence of the former on the latter, in terms of income and employment promotion, and of energy use.
}

gaps existing in countries and, consequently, in cities. According to Nussbaumer et al. [31], energy services are needed, but it is an insufficient element for human emancipation; moreover, these services can meet many basic needs, while the energy services alone do not reduce poverty in the world.

In order to allow some socioeconomic variables to be suitable to the eight MDGs, they were studied as proposed by the UN considering the metropolitan region of Paraíba Valley and Northern Coast as a case study, and it was sought to correlate them through factors containing the largest possible variability in the composition of the original variables. A descriptive evaluation of the available data for this metropolitan region is initially presented, followed by the statement of the necessary elements of multivariate analysis (factor analysis).

\subsection{The metropolitan region of Paraíba Valley and Northern Coast}

The metropolitan region of Paraiba Valley and Northern Coast (MRPV), located at the East cone of the São Paulo State (Fig. 5), in the Southeast region of Brazil, was chosen for this study due to presenting a concentration of predominantly urban cities and having metropolitan dimensions in terms of growth, social issues, and economic and environmental problems. The cities of the MRPV were highlighted, studied, and then divided into government areas by hub cities and their neighboring towns ( Table 1).

Neighboring cities were considered as the ones that have their economy highly associated with those of hub cities, with a dependency relationship with one another's economies and especially, with their predominantly urban features (Fig. 6). This means that the relationship between land use and the number of inhabitants of cities will not be the only factor to be taken into account. In addition, the economic characteristics (industry, commerce and services) predominate as urban activities. The governments of the Northern Coast cities (Caraguatatuba, Ubatuba, São Sebastião and Ilha Bela) are going to be excluded in this study due to a geographical issue, once the Serra do Mar physically limits them, and they are focused predominantly on touristic and commercial economic features.

From the cities in the MRPV (Table 1), the main socio-economic available data were extracted from the databases of public information research institutions associated with the federal government and the São Paulo State, in addition to international institutions, as described in Table 2.

From databases available in the institutions listed in Table 2. MDGs associated to the cities in the MRPV that were based on aspects of human dignity (Life) and energy use (Electricity) were identified, as shown in Fig. 6. This analysis were done seeking to understand the opportunities that can be offered to cities lacking in planning in the region in order to meet the aspirations of the countries that make up the UN regarding the MDGs. From energy use, only the electric energy that is suitable to analyses intended to be conducted along this study is characterized because of the availability of the used databases, which inform power 
consumption of cities more consistently, and have more consolidated historical information (relative to 2012, according [32]).

\subsection{Factor analysis}

Factor analysis is a statistical technique in order to clarify a set of variables in common factors for better explaining the characteristics of these variables. In other words, the set of variables is reduced to a smaller set of factors, each of them composed of variables highly correlated with each other and weakly associated to the variables present in the other factors [42]. Mathematically, this is obtained by a linear combination of these factors plus an associated error, according to Eq. (1).

$Z=\left(Z_{p}\right)^{t}=\sum_{k=1}^{n} \lambda_{k} * F_{k}+\varepsilon_{k}, \forall p: 1 \ldots k$

in which $Z$ is a dependent variable explained by factors $F_{k}$ (the vector of the $p$ th standardized variables $\left.\left[Z_{p}=\left(X_{p}-\mu_{p}\right) / \sigma_{p}\right] \sim N(0,1)\right], X_{p}$ represents the $p$ th studied variable, and $\mu_{p}$ e $\sigma_{p}$ are the mean and the standard deviation values of $\left.X_{p}\right) ; \lambda_{k}$ are the eigenvalues associated to eigenvectors $\left(F_{k}\right)$ generated by a linear transformation of $X_{p} ; \varepsilon_{k}$ is the error associated with the linear transformation of $X_{p}$ (in general, it follows a random variable with mean zero and variance 1 , which composes the unexplained portion by factors $F_{k}$ ).

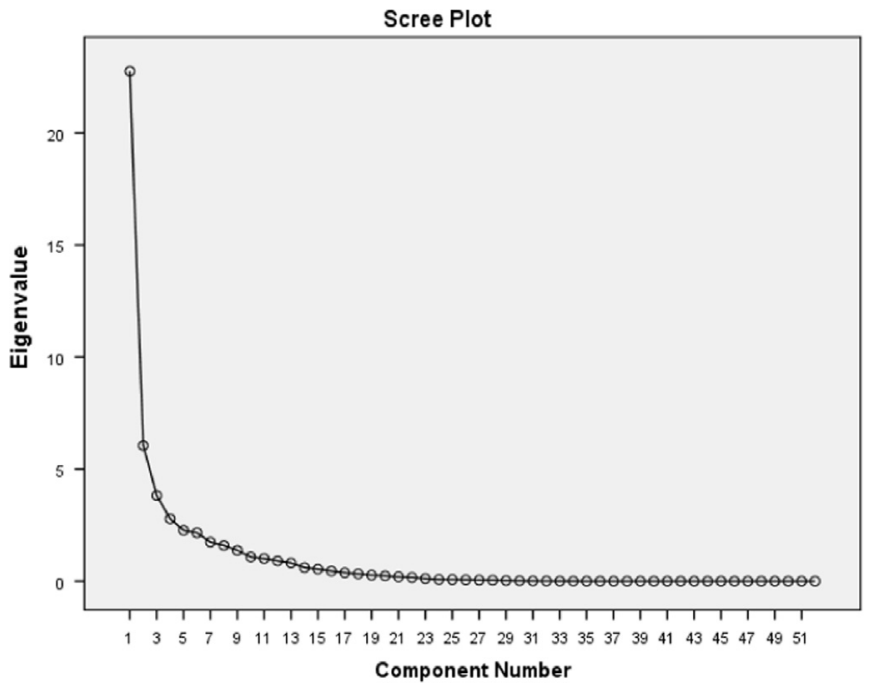

Fig. 7. Scree-plot chart.
This technique should be applied to evaluations that contain large sets of variables. The main objective is to reduce a great deal of information in the case, represented by variables $X_{p}$, into a smaller number of new variables, represented by factors $F_{k}$. It is expected that the variability contained in $X_{p}$ is represented (the greatest portion as possible) in factors $F_{k}$. For this, it is necessary that these original variables be mutually correlated in order to evidence their characteristics in factors created by the factor analysis.

The variability of $X_{p}$ is represented by $\lambda_{k}^{2}$, which comes from covariance matrix $\left(\sum\right)$, in a way that $\sum=\Lambda \Lambda^{t}$, in which $\Lambda$ is the matrix of eigenvalues $\lambda_{k}$ (also called factor loading matrix) determines eigenvectors $\xi_{k}$. Thus, for calculating eigenvalues $\lambda_{k}$, it is used the determinant $\mid \sum-\Lambda I=0$ and, for eigenvectors $\xi_{k}$, it is utilized $\left(\sum-\Lambda I\right) * \xi=0$ Hence, the eigenvectors determine the directions of maximum variability and the eigenvalues specify the variances. This is possible after the composition of a linear combination of the original variables with the intention of evidencing correlations that exist between the original variables, and later associating them with possible common generated factors.

There are two kinds of factor analysis, the exploratory and the confirmatory. The former must combine the main factors generated from the characteristics of the initial variables, so that there are not a number of factors as reference to be found, and the latter suggests comparing and confirming, before a predefined theoretical model, whether the data is attached to the model [43]. To apply this method and, afterwards, potentially obtaining practical results, the variables must be normalized to generate standardized variables, that is, variables must be subtracted by their respective mean and then divided by its standard deviation using Eq. (1).

For the implementation of factor analysis, Sewell [44] suggests a few steps, namely

a. Allocation of variables to be selected;

b. Consistent and adequate sampling to variables;

c. Construction of the covariance matrix and correlations between variables;

d. Definition of the quantity of factors;

e. Determination of whether factors can be correlated or not;

f. Choice and implementation of factors rotation;

g. Possible feedback from the initial problem;

h. Interpretation of the structure generated by the factors;

i. Post-evaluation of the use of factors and their loads for further analysis.

There are also two supplementary analyses associated with the factor analysis: the principal component analysis and the common

Table 3

Example of the total variance explained by the eigenvalues on the factor analysis.

\begin{tabular}{|c|c|c|c|c|c|c|}
\hline \multirow[t]{2}{*}{ Component } & \multicolumn{3}{|c|}{ Initial eigenvalues } & \multicolumn{3}{|c|}{ Extraction sums of squared loadings } \\
\hline & Total & $\%$ of Variance & Cumulative \% & Total & $\%$ of Variance & Cumulative \% \\
\hline 1 & 22.75 & 43.75 & 43.75 & 22.75 & 43.75 & 43.75 \\
\hline 2 & 6.04 & 11.63 & 55.38 & 6.04 & 11.63 & 55.38 \\
\hline 3 & 3.82 & 7.35 & 62.74 & 3.82 & 7.35 & 62.74 \\
\hline 4 & 2.78 & 5.34 & 68.08 & 2.78 & 5.34 & 68.08 \\
\hline 5 & 2.27 & 4.36 & 72.45 & 2.27 & 4.36 & 72.45 \\
\hline 6 & 2.16 & 4.16 & 76.61 & 2.16 & 4.16 & 76.61 \\
\hline 7 & 1.74 & 3.35 & 79.96 & 1.74 & 3.35 & 79.96 \\
\hline 8 & 1.59 & 3.06 & 83.03 & 1.59 & 3.06 & 83.03 \\
\hline 9 & 1.37 & 2.63 & 85.66 & 1.37 & 2.63 & 85.66 \\
\hline 10 & 1.08 & 2.07 & 87.74 & 1.08 & 2.07 & 87.74 \\
\hline 11 & 1.01 & 1.94 & 89.68 & 1.01 & 1.94 & 89.68 \\
\hline 12 & 0.91 & 1.74 & 91.43 & & & \\
\hline
\end{tabular}

Extraction Method: Principal Component Analysis. 
factors analysis. In both cases, the goal is to analyze large amounts of data and seeking to account for the variables in a smaller number of factors, with minimal information loss. Based on formulations of [45-47], the factor analysis is structured as

$\left\{\begin{array}{c}Z_{1}=\lambda_{11} F_{1}+\lambda_{12} F_{2}+\ldots+\lambda_{1 n} F_{n}+\varepsilon_{1} \\ Z_{2}=\lambda_{21} F_{1}+\lambda_{22} F_{2}+\ldots+\lambda_{2 n} F_{n}+\varepsilon_{2} \\ \vdots \\ Z_{p}=\lambda_{p 1} F_{1}+\lambda_{p 2} F_{2}+\ldots+\lambda_{p n} F_{n}+\varepsilon_{p}\end{array}\right.$

In this case, $F_{n}$ represents the $n$th factor generated by the factor analysis, which contains the maximum possible variability present in variable $X_{p x 1}$. The vector $\varepsilon=\left(\varepsilon_{1}, \varepsilon_{2}, \ldots, \varepsilon_{p}\right)^{t}$ identify the error associated with the information loss present in the factor analysis. It is expected that these are minimized on the analysis so that they obtain a mean of zero and variance $1 ; \lambda_{p n}$ is the eigenvalue associated with the $p$ th variable and the $n$th factor created by the factor analysis.

The choice of these $n$ factors can follow criteria that consider the relationship between the total variability present in the original variables and the eigenvalues of the chosen factors. The lower the factor load (eigenvalue) is, the lesser their representativeness of the created factor becomes. The scree plot chart analysis is used as a tool for determining the number of factors. Each eigenvalue $\lambda$ is presented in descending order on the scree plot chart and is related to its according variables (Fig. 7). $\lambda_{i} / \operatorname{Sum}\left[\lambda_{i}\right]$ (for all $i=1-n$ ) is associated with each factor, which allows choosing the number of factors by the variability of these relative eigenvalues (Table 3).

The number of factors to be considered will be that which the eigenvalue associated with each factor (eigenvectors) has a value that is greater than 1 (process known as Kaiser normalization [45]), and the total variance is explained by the main components, which can be verified by means of Table 3. In addition, the accumulated variance contained in the selected factors should be greater than $60 \%$ [45], otherwise the variables associated with the factors will be deleted from the analysis. For the sake of confirmation of the number of factors, it was also used the curvature displayed on the scree plot, in which there is a minimal variation, and then the number of factors can be determined.

As shown in Table 3, factors between 9 and 13 were assumed where it is observed the number of 11 factors, as it is the number of eigenvalues that is greater than 1 . With a software available for statistical data analysis, such as the Statistical Package for Social Science (SPSS), there is the possibility of determining factors with an eigenvalue that is greater than 1 [48], as well as it is possible to check the percentage of the accumulated variability present in the factors by means of result reports. This ensures that the chosen factors well represent the variability present in the original variables.

In Table 3, it is understood that the eigenvalue of the first component (line 1 ) is 22.75 and this is the decrease that is exposed between the first and the second component in Fig. 5; in terms of variability, this is representative that the first component contains $43.75 \%$ of the total variability present in the original variables. These values are calculated until the eigenvalue is less than 1 , which defines the extraction of factors representing the original variables. In this example, it represents 11 selected factors, with $89.68 \%$ of the total variability present in the original variables.

\subsubsection{Factor rotation}

As suggested by Sewell [44], step $f$ of the factor analysis implementation refers to the rotation of factors. Rotation is a linear transformation of the extracted factors on the factor analysis, so that the explanations given by the factors are subjected to an arrangement of variables that are better correlated to that factor. The goal is to refine the analysis and to enable the inclusion of variables that were not included before the rotation of factors. IBM software - SPSS 20 presents a few rotation methods (orthogonal or oblique rotation methods): Varimax, Quartimax, Equamax, Direct Oblimin and Promax. In practice, it is assumed that, for orthogonal rotations, the generated factors are considered as being noncorrelated. On the other hand, oblique rotations assume a degree of correlation between the selected factors.

3.4.1.1. Orthogonal rotations. The method that is mostly used is the Varimax, which allows a minimization of the number of variables that each factor will have, thus simplifying the interpretation of factors. The Quartimax method is another type with the objective of minimizing the number of factors needed to explain a variable, as well as the Varimax method, which presents a simplified explanation of variables. The Equamax method represents features merged between the Varimax and the Quartimax. Its main feature

Table 5

Human development levels according to the HDI value.

Source: [1]

\begin{tabular}{ll}
\hline HDI value & Human development level \\
\hline$[0.000,0.500)$ & Very low \\
{$[0.500,0.600)$} & Low \\
{$[0.600,0.700)$} & Average \\
{$[0.700,0.800)$} & High \\
{$[0.800,1.000)$} & Very high \\
\hline
\end{tabular}

Table 4

Initial descriptive statistics of the MRPV - refers to 2010-2013.

Source: [32,33]

\begin{tabular}{|c|c|c|c|c|c|c|c|c|c|}
\hline & & $\begin{array}{l}\text { Estimated popula- } \\
\text { tion } 2013\end{array}$ & HDI 2010 & $\begin{array}{l}\text { GDP (USS mil- } \\
\text { lion) } 2011\end{array}$ & $\begin{array}{l}\text { Illiteracy (\%) } \\
2010\end{array}$ & $\begin{array}{l}\text { Resident population in } \\
\text { urban area (\%) } 2010\end{array}$ & $\begin{array}{l}\text { Water supply } \\
\text { (\%) } 2010\end{array}$ & $\begin{array}{l}\text { Sewage (\%) } \\
2010\end{array}$ & $\begin{array}{l}\text { Garbage collection } \\
\text { (\%) } 2010\end{array}$ \\
\hline \multicolumn{2}{|l|}{$N$} & 35 & 35 & 35 & 35 & 35 & 35 & 35 & 35 \\
\hline \multicolumn{2}{|l|}{ Mean } & 57,698 & 0.730 & 584.21 & 6.89 & 76.69 & 95.82 & 85.43 & 99.35 \\
\hline \multicolumn{2}{|l|}{ Mode } & 2481 & 0.690 & - & 2.86 & 98.60 & 76.40 & 77.98 & 99.47 \\
\hline \multicolumn{2}{|c|}{ Std. deviation } & 119,328 & 0.042 & 1598.21 & 3.24 & 20.36 & 5.41 & 12.97 & 0.55 \\
\hline \multicolumn{2}{|l|}{ Range } & 634,395 & 0.150 & 8620.61 & 13.70 & 69.18 & 23.14 & 47.42 & 2.16 \\
\hline \multicolumn{2}{|l|}{ Minimum } & 2,481 & 0.650 & 12.13 & 2.86 & 30.20 & 76.40 & 50.56 & 97.72 \\
\hline \multicolumn{2}{|l|}{ Maximum } & 636,876 & 0.810 & 8632.75 & 16.56 & 99.38 & 99.54 & 97.98 & 99.88 \\
\hline \multicolumn{2}{|l|}{ Sum } & $2,019,438$ & - & $20,447.48$ & - & - & - & - & - \\
\hline \multirow[t]{5}{*}{ Percentiles } & 10 & 3986 & 0.680 & 15.33 & 3.02 & 46.02 & 86.41 & 61.41 & 98.29 \\
\hline & 25 & 5913 & 0.700 & 27.02 & 3.87 & 59.43 & 96.46 & 79.40 & 99.34 \\
\hline & 50 & 11,740 & 0.730 & 51.44 & 6.52 & 81.70 & 98.13 & 90.02 & 99.53 \\
\hline & 75 & 48,497 & 0.770 & 268.50 & 9.96 & 95.30 & 98.77 & 94.95 & 99.75 \\
\hline & 90 & 177,910 & 0.790 & $1,663.33$ & 10.66 & 98.24 & 99.32 & 97.19 & 99.82 \\
\hline
\end{tabular}




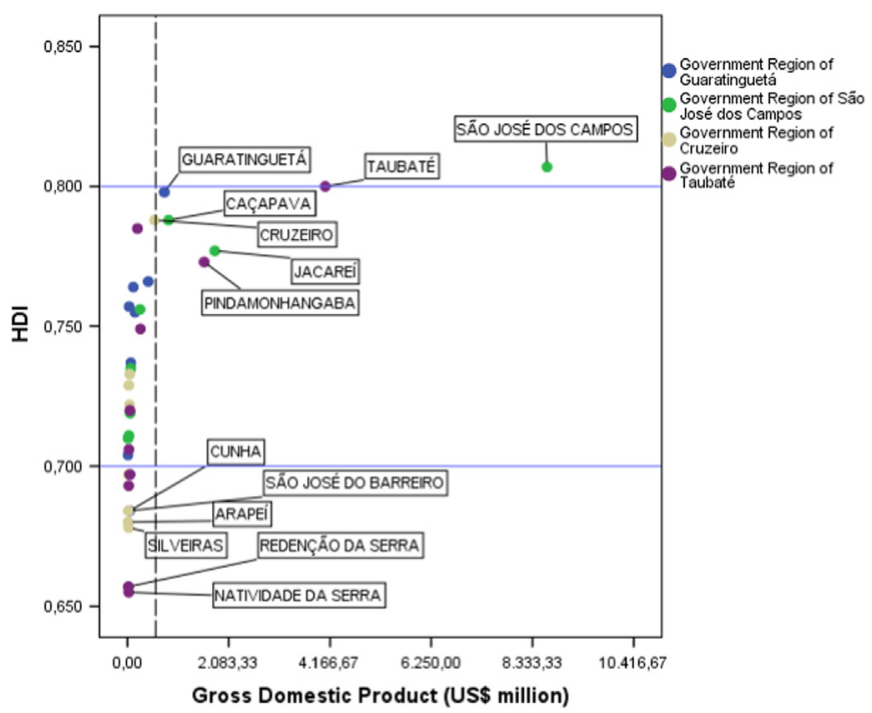

Fig. 8. HDI (2010) versus GDP (2011) of the cities of the MRPV.

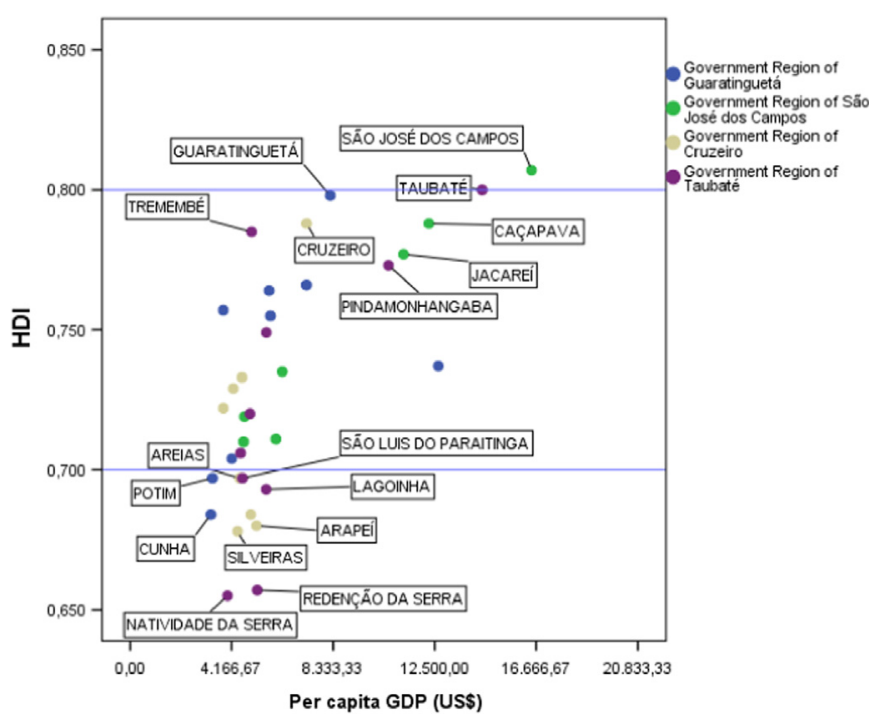

Fig. 9. HDI (2010) versus Per capita GDP (2011) of the cities of the MRPV.

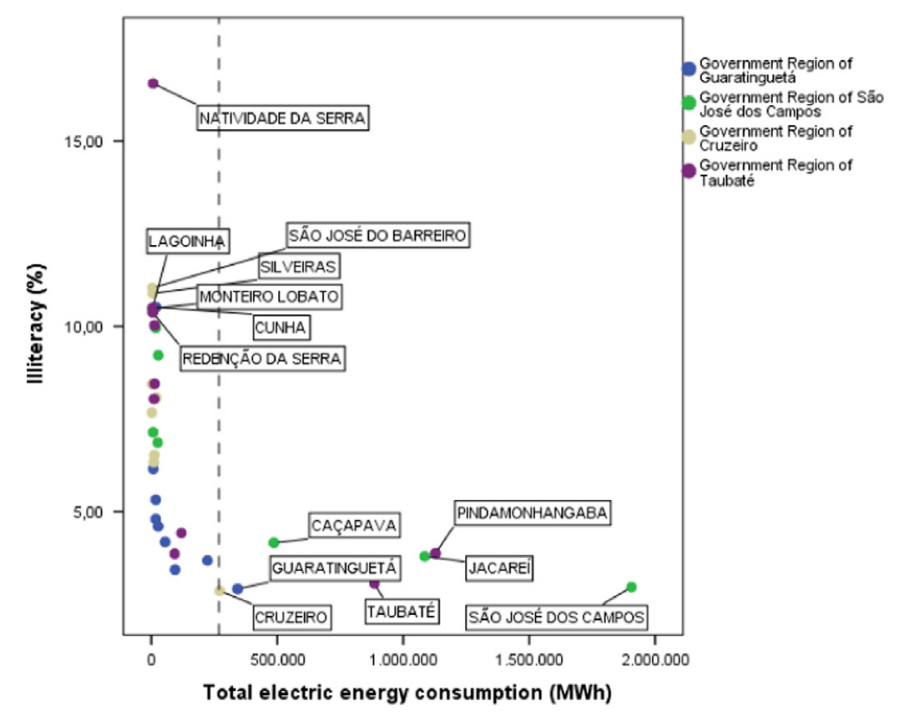

Fig. 10. lliteracy (2010) versus Total electric energy consumption (2012) in the MRPV.

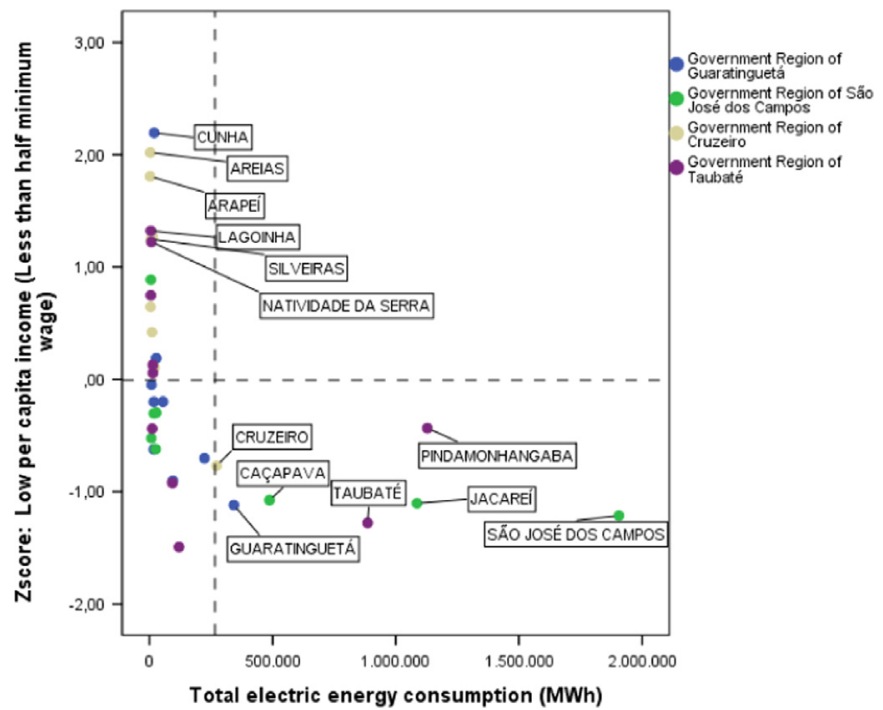

Fig. 11. Low per capita income (2013) versus Total electric energy consumption (2012).

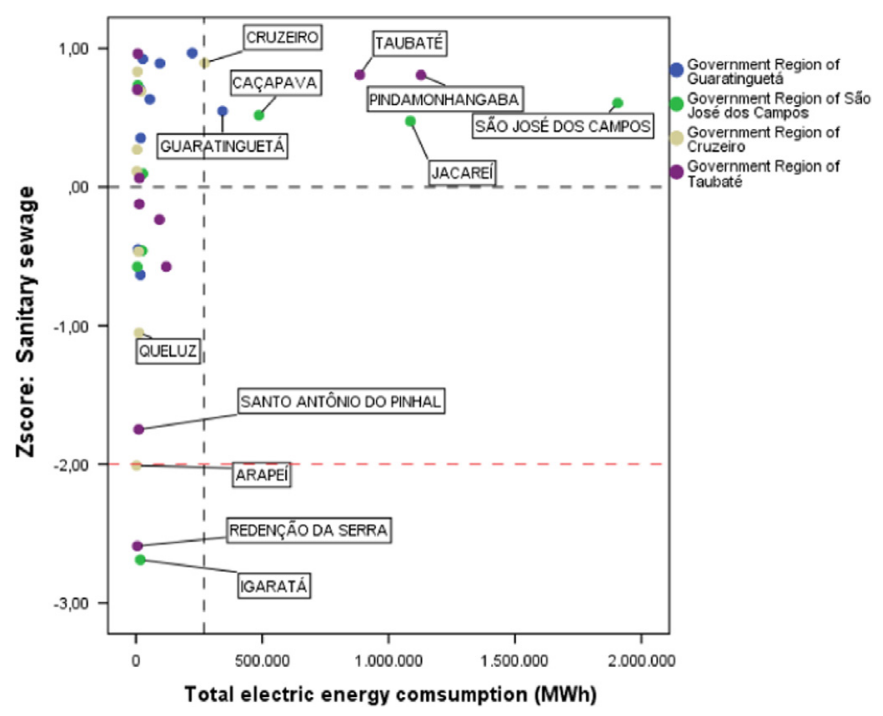

Fig. 12. Sanitary sewage (2010) versus total electric energy consumption (2012).

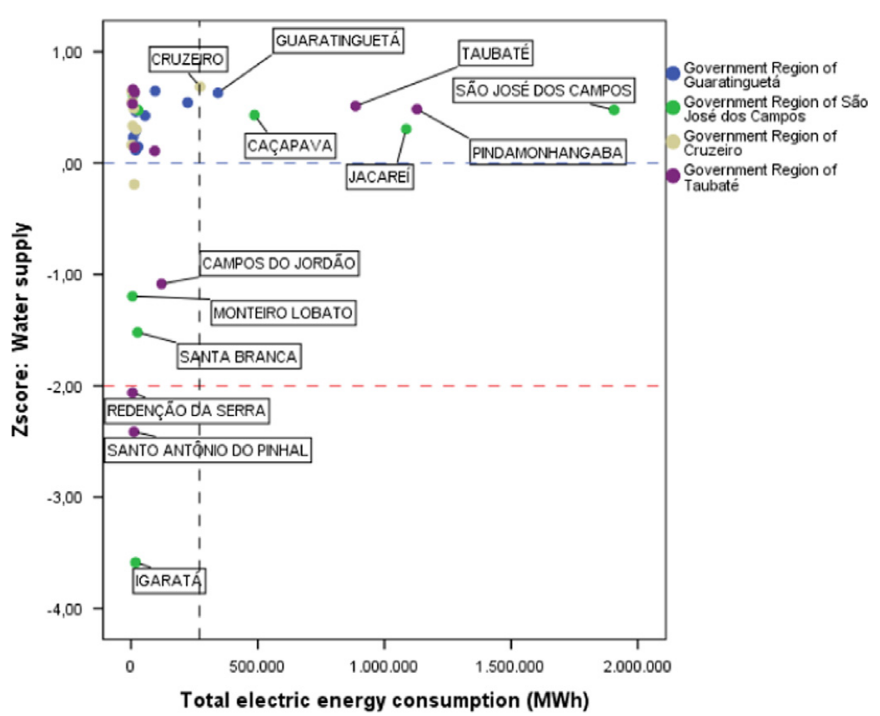

Fig. 13. Water supply (2010) versus total electric energy consumption (2012). 


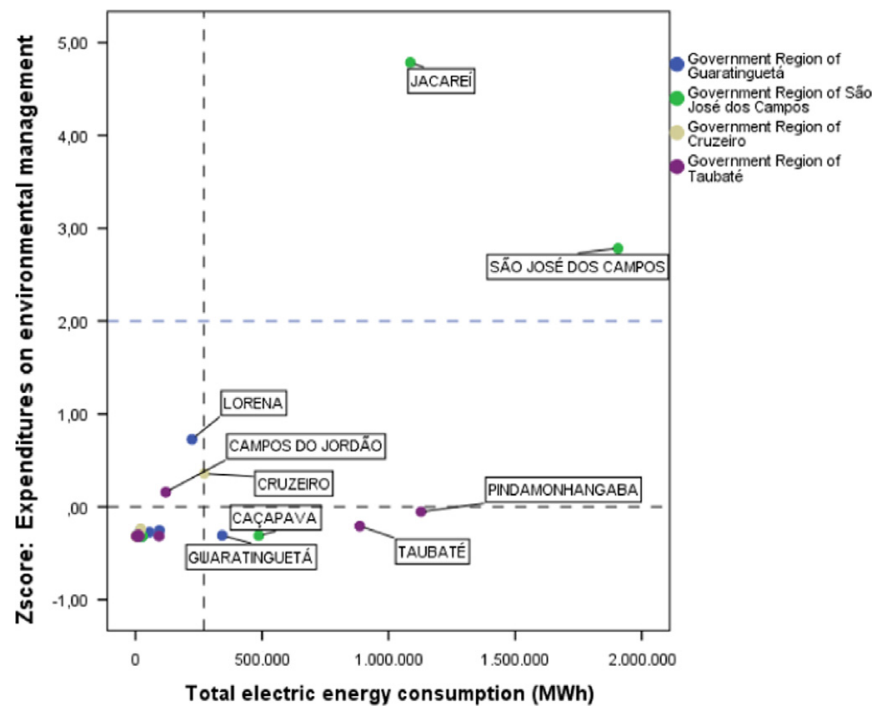

Fig. 14. Expenditures on environmental management (2011) versus total electric energy consumption (2012).

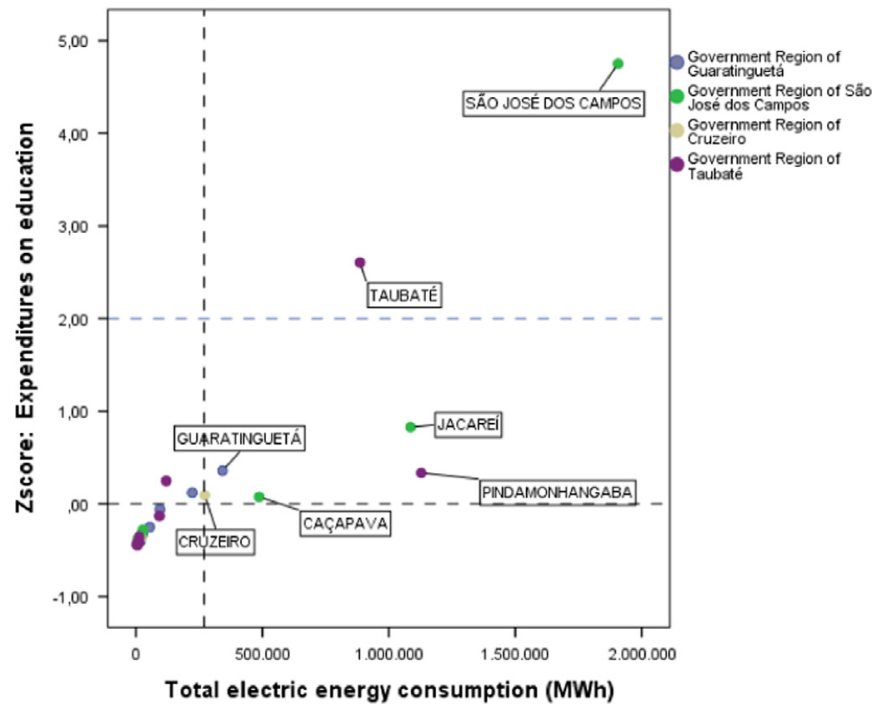

Fig. 15. Expenditures on education (2011) versus total electric energy consumption (2012). is the load explained in greater factors, and so the number of factors will be minimized. On a qualitative approach, the orthogonal rotation represents the possibility of improvement in understanding the inclusion (or confirmation of exclusion) of a decision variable that composes a factor. This can occur if the correlation of variables on each extracted component is significantly altered in order to modify the arrangement of variables that make up a factor.

3.4.1.2. Oblique rotations. Among the oblique rotations available on the IBM-SPSS 20 software, there is the Direct Oblimin rotation, which is applied to factors that are not yet well explained by orthogonal rotations, or even to justify the condition of orthogonality in found factors. The Direct Oblimin rotation depends on the attribution of a parameter $\delta$ (delta); the more negative this parameter is, the lesser the oblique factors will be (generally, it is assumed $\delta<0.8$ [48]).

Another available method is the Promax, from which the characterization of correlated factors can be extracted, and must be applied to a data set with many variables. As the Oblimin, it depends on parameter $\kappa$ (kappa), which, in most applications, is used with a value of 4 [48]. Qualitatively, the oblique rotation can signal the non-orthogonality between a few factors selected by the orthogonal rotation, or those that are not well explained by it; or even to stick to the possibility of existence of correlated factors, whenever it is appropriate in the analysis.

For this article, the Varimax orthogonal rotation is used because it is aimed at minimizing the number of variables of each factor, which is determined by the factor analysis with the principal component extraction method. This leads to the analysis of possibilities that are less questionable with regard to the selected variables that make up each factor, and is consistent with the arguments presented by Martchamadol and Kumar [29].

The rotation of factors allows observing which factors are increased as for the degree of explanation of the original variables, and which do not represent significant changes. It represents a confirmation of the initial principal components matrix or indicates improvements on the analysis.

\section{Results}

The São Paulo State (SPS), with a population growth rate of approximately $1.09 \%$ per annum, represents $21.6 \%$ of the total

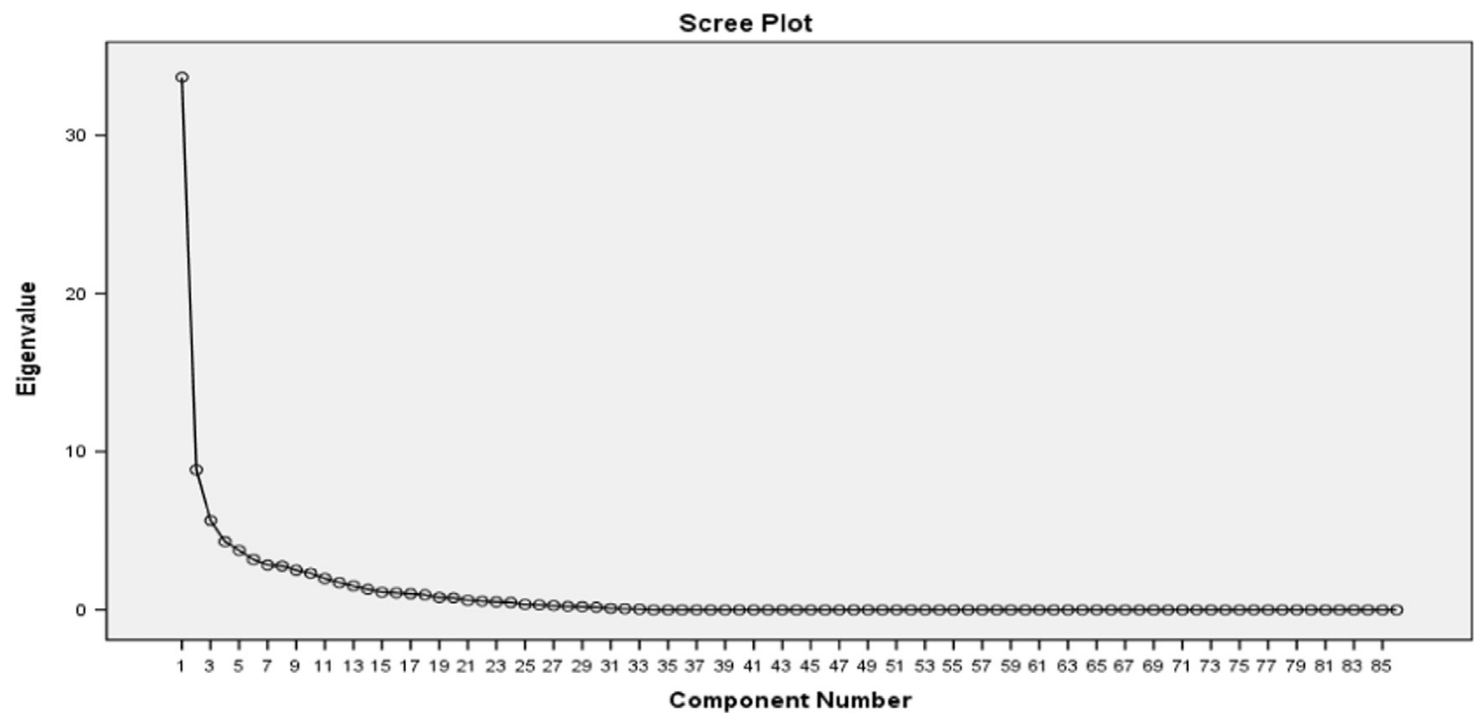

Fig. 16. Scree plot. 
Table 6

Rotated components matrix with consolidated factors.

$N$ Consolidated factor

1 The factor shows the high level of relationship among income, population density and power consumption, while the number of people attended by basic health units (BHUs) is preposterous.

\section{Variables associated with}

Demographic density (0.551)

Environmental management expenses (0.574)

Expenses with education (0.971)

Expenses with health (0.976)

Population (0.969)

GDP (0.984)

AIDS (number of cases) (0.880)

BHU (0.761); Individuals attended in UBSs (-0.625)

Doctors SUS (0.578)

Hospital beds $(0.956)$

MWh Industry (0.692)/Consumers (0.932)

MWh Residences (0.972)

MWh Commerce (0.982)/ Consumers (0.976)

MWh Public lighting and services (0.957)/ Con-

sumers (0.962)

GDP Industry (0.981)

GDP Commerce and Services (0.984)

Urban and Rural Residences (0.974)

Women without any monthly income (0.967)

Women Income in Industry (0.516)

Women Income in Commerce (0.501)

Industry Income (0.666)

Commer Income $(0.555)$

Services Income $(0.566)$

Born alive (0.974)

2 This factor shows that some areas of government have high HDI values, with proper sanitation, coupled with a high per capita consumption of energy in residential and commercial sectors, in contrast with high illiteracy rates, towards a high social vulnerability, extreme poverty and low per capita consumption of electricity in the rural sector.

This factor indicates that elderly care has been in contrast with industrial energy intensity, towards populations with high social vulnerability, especially in rural areas households.

4 The factor is suitable especially to populations with above-average per capita income, with no social vulnerability.

5 The income of women is focus of this selected factor, associated mainly to the service sector, and high rates of infant mortality.

6 The factor is directly related to irregular land occupation, and residences located in hazardous areas.

7 The factor indicates that the power consumption of the rural sector is characterized by the small number of rural residences.

8 The factor is related to essential services to human dignity, ensuring access to drinking water, sanitation and urban waste collection.

9 The factor is associated with the municipal expenditure with transport and the per capita consumption of the industrial sector

10 The small number of hospital beds and the rural sector's energy intensity form this factor.

11 Life expectancy is the main feature of this factor that tackles the issue of elderly care under aspects of social protection.

12 The factor is characterized by the expenses with environmental and sanitation management in the areas of government.

13 The factor characterizes the occurrence rate of adolescent mothers who are usually in school age.

14 Electric energy intensity in commerce and services moverty $(-0.786)$

HDI (0.835)

Illiteracy (-0.860)/Average years of study (0.829)

Urban and Rural Residences (0.775)

Doctors SUS (0.538)

Residences per capita MWh (0.818)

Commerce per capita MWh (0.616)

Public lighting and services per capita MWh (0.524)

Rural MWh (-0.501)

IPVS - Very high vulnerability (-0.836)

IPRS-Wealth Dimension (0.722)

Women Income in Industry (0.506)

Women Income in Commerce (0.602)

Women Income in Civil construction (0.608)

Adequate sanitation (0.767)

Income in Commerce $(0.588)$

Futurity index - Participation (0.511)

Industrial Energy intensity $(-0.775)$

Ageing index (0.680)

Urban and Rural Residences $(-0.602 /-0.897)$

IPVS - High Vulnerability (\% of the exposed population $(-0.822)$

Futurity index - Health (0.734)

IPVS - No Vulnerability (0.829)

GDP per capita $(0.918)$

Agricultural income (0.505)

nfant Mortality $(0.541)$

Women Income (0.684)

Women Income in Services $(0.840)$

ServicesIncome (0.652)

Irregular land occupation (0.889)

Rural per capita MWh (0.942)

Rural MWh (0.870)

Water supply (0.907)

Sanitary sewage (0.897)

Garbage collection $(0.714)$

Municipal expenses with transport (0.822)

Industry per capita MWh (0.579)

Rural Sector Energy Intensity (0.548)

Hospital beds (0.774)

uturity index (0.869)

Futurity index - Social Protection (0.914)

Municipal expenses with environmental management $(0.753)$

Municipal expenses with sanitation (0.871)

Adolescent mothers (-0.742)

Electric Energy Intensity in Commerce and Services $(-0.659)$
Urban and Rural Residences (0.601) 
Table 6 (continued)

N Consolidated factor
Variables associated with

15 The factor deals about women and their children's health care at birth, as indicators of children born with low Women and their children's health care (0.763) birth weight and brought up in a high social inequality scenario.

16 The factor indicates the elements related to extreme poverty and social inequality present in the hub cities Gini Index (0.884) and their neighboring towns.

17 Women's agricultural income characterizes the composition of families that are supported by wor workforce, even though wages are still not equivalent to those suggested to men.
Women's agricultural income (0.713)

Agricultural income $(0.524)$

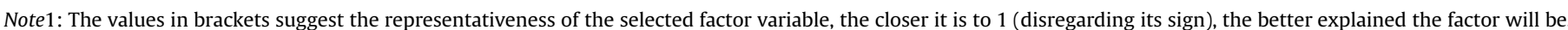

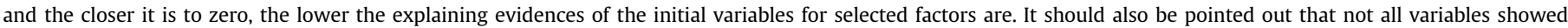
significant correlations for the factor analysis, and these were not presented within this table.

Brazilian population, while the total Brazilian population grows $1.19 \%$ per annum. In terms of urbanization rate, $95.94 \%$ of cities in the SPS are urbanized, while the same rate is 84.36\% [32] in Brazil. These aspects are important to explain the reason why cities of the MRPV have similar characteristics to the SSP in terms of population growth. In 2013, it presented a population of 2.33 million citizens, with a growth rate of $1.05 \%$ per annum [32].

In addition to these population data, other important values were also used for a later analysis of this article in Section 4.2. The analyses of the initial descriptive statistics of the cities of the MRPV can be summarized in Table 4, from which it can be evidenced the values of the population, HDI, GDP, illiteracy rate, population residing in urban areas, water supply, sanitation and garbage collection. The UN uses a scale to evaluate the HDI values (Table 5), from which insights regarding citizens longevity (life expectancy), education (literacy and expectation in years of study) and income (wealth accumulated over a period of time by the various sectors of the economies of cities or countries) can be extracted [1].

From a comparison between the GDP and HDI, as it was used by Goldemberg [11], Charpentier [30] and Charpentier and Beujean [49] in clear attempts to explain the disparities between developed and developing countries, it was made a similar comparison. The intention for this was highlighting any relevant differentiation between the most industrialized cities (hub cities and other industrialized neighboring towns) of the MRPV government regions, or of cities with economies geared to services, or even cities with typically rural features in which its human development is considered as being medium or low, according to the scale in Table 5.

In terms of power intensity, the relationship between the total electric energy consumption of cities and aspects regarding basic social needs are accentuated, such as sanitation, garbage collection, water supply, illiteracy rates, infant mortality and income; the economic aspect related to industrial production also characterizes the cities. From an association between the GDP and HDI (see Figs. 8 and 9), the hub cities and some of their industrialized neighboring towns (São José dos Campos, Taubaté, Guaratinguetá, Cruzeiro, Caçapava, Jacareí and Pindamonhangaba) are highlighted in a relationship that identifies that, the higher the GDP value is, the higher its HDI value becomes. This occurs even in cities with a low GDP, as Guaratinguetá and Cruzeiro, which present a high HDI value.

If a comparison is made among cities according to their degree of urbanization presented in Fig. 9, there is a lower GDP value, which is considered as moderate when compared to cities with lower degrees of urbanization. The characteristics of GDP versus HDI remain unchanged, even if cities with lower GDP values are taken into account, and this leads to a higher HDI value; this feature is more distinctive for the most industrialized cities in the region, including the hub cities.

Regarding energy use, it is drawn relationships among electricity consumption and illiteracy rate, percentage of people living with per capita income less than half of the minimum wage, percentage of people with adequate sewage, percentage of people with access to safe drinking water, environmental management costs and expenses with education of cities of the MRPV from Figs. 10 to 16 . Thereby, some energy characteristics of cities suggest possible interferences on pressing social needs. Thus, one can confront the urbanization mode and the choices of the hub cities and their neighboring towns by economic models that always handled their growth as a singular element, even when it neither represents its totality, nor meets the demands of the majority of the population of these cities, in their areas of government and adjoining borders.

The relationships of Figs. 11-15 take into account the $Z$ scores variables, with the exception of the total consumption of power, which is kept in real dimension on the horizontal axis. The $Z$ scores represent the standardization of the variable compared with the mean and standard deviation of variable (Zscore $=(x-x) / \sigma$, in which $x$ is the value of variable $X_{,}^{-} x$ is the mean of these observations in $X$ and $\sigma$ is the standard deviation). This procedure allows the identification of possible discrepancies in the studied variables, and in this case, the aim is to identify the discrepancies between the cities of the MRPV in their socioeconomic aspects regarding power consumption.

\subsection{Factor analysis: principal component extraction}

Once the results of the factor analysis with the principal component extraction are found with the use of the IBM SPSS Statistics 20 software, the scree plot (Fig. 16) is presented and the report of the eigenvalues selected to represent the load variability suggested by the factor analysis through the explained variance (Tables 6 and 7 ). Based on these results, it was concluded that 17 is the number of factors that better represents the 86 variables for the 35 cities in the MRPV, subdivided into four government areas (Table 1 ), since the eigenvalues that are greater than 1 occur among the first 17 factors, and this means a variance of $91.43 \%$ of the original variables.

A rotation of the component matrix is quite necessary since the rotated components matrix overrides the first one by suggesting a better explanation of the factors for the original variables of the problem. Correlation values that are greater than 0.50 were included in the rotated matrix, being that 17 factors were evidenced in it since correlations that are less than 0.50 indicate a weak relationship between the selected factors and the original variables whereas, in the components matrix without rotation, only 10 factors were selected to explain the original variables. From these matrixes, Table 6 was composed, in which it is extracted the consolidation of factors that contains the greatest load of variability present in the original variables of the problem.

Seventeen factors were determined in accordance with the characteristics of variables that are better explained by these factors. From the values in parentheses shown in Table 6, it is understood how the variable is represented by the given factor; 
Table 7

Total variance explained.

\begin{tabular}{|c|c|c|c|c|c|c|c|c|c|}
\hline & \multicolumn{3}{|c|}{ Initial eigenvalues } & \multicolumn{3}{|c|}{ Extraction sums of squared loadings } & \multicolumn{3}{|c|}{ Rotation sums of squared loadings } \\
\hline & Total & $\%$ of Variance & Cumulative \% & Total & $\%$ of Variance & Cumulative \% & Total & $\%$ of Variance & Cumulative \% \\
\hline 1 & 33.65 & 39.13 & 39.13 & 33.65 & 39.13 & 39.13 & 25.73 & 29.92 & 29.92 \\
\hline 2 & 8.84 & 10.28 & 49.42 & 8.84 & 10.28 & 49.42 & 12.08 & 14.05 & 43.97 \\
\hline 3 & 5.65 & 6.57 & 55.99 & 5.65 & 6.57 & 55.99 & 5.36 & 6.23 & 50.21 \\
\hline 4 & 4.32 & 5.02 & 61.01 & 4.32 & 5.02 & 61.01 & 3.83 & 4.45 & 54.66 \\
\hline 5 & 3.75 & 4.36 & 65.38 & 3.75 & 4.36 & 65.38 & 3.58 & 4.17 & 58.83 \\
\hline 6 & 3.18 & 3.70 & 69.08 & 3.18 & 3.70 & 69.08 & 3.17 & 3.68 & 62.52 \\
\hline 7 & 2.83 & 3.29 & 72.38 & 2.83 & 3.29 & 72.38 & 3.16 & 3.68 & 66.20 \\
\hline 8 & 2.78 & 3.23 & 75.61 & 2.78 & 3.23 & 75.61 & 3.08 & 3.58 & 69.79 \\
\hline 9 & 2.50 & 2.91 & 78.52 & 2.50 & 2.91 & 78.52 & 2.53 & 2.94 & 72.74 \\
\hline 10 & 2.31 & 2.69 & 81.21 & 2.31 & 2.69 & 81.21 & 2.50 & 2.91 & 75.65 \\
\hline 11 & 1.98 & 2.30 & 83.52 & 1.98 & 2.30 & 83.52 & 2.50 & 2.90 & 78.56 \\
\hline 12 & 1.72 & 2.00 & 85.52 & 1.72 & 2.00 & 85.52 & 2.20 & 2.56 & 81.12 \\
\hline 13 & 1.52 & 1.77 & 87.30 & 1.52 & 1.77 & 87.30 & 2.13 & 2.48 & 83.61 \\
\hline 14 & 1.30 & 1.51 & 88.81 & 1.30 & 1.51 & 88.81 & 2.05 & 2.38 & 86.00 \\
\hline 15 & 1.11 & 1.29 & 90.11 & 1.11 & 1.29 & 90.11 & 2.03 & 2.36 & 88.37 \\
\hline 16 & 1.07 & 1.25 & 91.37 & 1.07 & 1.25 & 91.37 & 1.89 & 2.20 & 90.58 \\
\hline 17 & 1.02 & 1.18 & 92.55 & 1.02 & 1.18 & 92.55 & 1.70 & 1.97 & 92.55 \\
\hline 18 & 0.95 & 1.10 & 93.66 & & & & & & \\
\hline
\end{tabular}

Extraction Method: Principal Component Analysis.

there is high emphasis on this piece of information when the values in parentheses are closer to 1 . It is from this understanding that the information must be extracted from the factor analysis. Subsequently, such information is associated with the MDGs by means of factors that meet the aspirations of the populations of cities that are the less affluent and more subject to inequalities and socioeconomic vulnerabilities, imposed by the growth modes proposed by hub cities and their respective government areas.

\subsection{Results analysis}

The cities of the MRPV presented urban characteristics that are very similar to those of hub cities - São Paulo and Rio de Janeiro and are related to their historical choices. Such choices re-edit social problems such as those occurring in peripheral cities to these great hubs. It is observed that there are similar characteristics among government areas determined by the degree of urbanization of hub cities and their major neighboring towns, mainly, and of strong industrialization. This is confirmed by factors selected by the factorial analysis (Table 7), which suggest interrelationships between the economies of the cities of the MRPV, the power consumption of the main sectors and priority social indicators (improvement in health care conditions, education and positive or negative effects as the inclusion of women in economic activities that allow improvements to their families).

Table 6 allows perceiving elements such as illiteracy, urban resident population, water supply, sanitation, garbage collection, HDI, GDP and resident population estimated as examples of the problems faced by the MRPV, as it is occurring in large metropolitan areas (as in the cities of São Paulo and Rio de Janeiro). Illiteracy, water supply, sewage and garbage collection rates diverge from one another in good factors and others that are not so good. For example, illiteracy in Brazil from 2013 data corresponds to 8.7\% [33], which means approximately 13.2 million people. This reflects on some less affluent cities to the MRPV: approximately $25 \%$ of the cities (i.e., above the third quartile, Table 4) in the region have illiteracy as a problem to be overcome, which is above the national rate of $9.96 \%$.

On the other hand, there are advances for the health service, as the fact that $97.72 \%$ of solid waste is collected in the cities, which reduces the proliferation of diseases especially regarding children, who are the most vulnerable. The same cannot be said for water supply and sanitary sewer collection that, in some cases, mainly cities around the MRPV, deserve greater attention because they present very unfavorable rates. In this way, about $25 \%$ of cities are serviced in $59.43 \%$ of the total population by water supply and $10 \%$ of cities have only $61.41 \%$ of the population served by sewage collection (Table 4).

These indicators occur in conditions of income difference (GDP) which are accentuated among cities. This is noted by a high standard deviation of the GDP of cities, which equals US\$1.598.21 million for a mean of US\$584.21 million. Similarly, urban resident population rates are significantly different among cities, represented by values of mean and standard deviation of $20.36 \%$ and $95.82 \%$, respectively. These values are consistent with the reality of the MRPV, consisting of industrialized and urban hub cities, wealthier in living conditions for the population and an evident social inequality in scenarios with high rates of illiteracy in typically rural towns with low availability of water supply and sewerage.

In the MRPV, regarding the relationship between human development and financial resources, HDI values classified by the UN are identified in Fig. 8 as very high or high (see Table 5) in cities with a higher level of urbanization, including the hub cities of the studied government regions. The tracks presented in Fig. 8 refer to the observation that most industrialized cities with the highest level of urbanization (over 88\%) located around the Paraiba do Sul River present greater wealth according to GDP. Otherwise, the towns that identify themselves as being typically rural, but with a moderate level of urbanization (between 55\% and 75\%) located on the boundary of the MRPV and that are either closer to the Serra da Mantiqueira (beside the Continent) or to the Serra do Mar (beside the Atlantic Ocean) have low GDP values. The vast majority of such towns is below the mean GDP value (US\$ 584 million), even though discrepancies related to the GDP of hub cities are inherent in this value, which means an expected GDP value that is even lower when considering just the less urbanized cities.

Certainly, the relationship between the aspects of improving basic human life condition and power consumption include illiteracy, per capita income of less than half of the minimum wage, service level of potable water supply and sewerage. In addition, it should be highlighted the investments of the cities of the MRPV in education and environmental management. 
From the relationship between electricity consumption (MWh) and illiteracy rate (see Fig. 10), it is observed, on the one hand, low illiteracy rates related to hub cities and some of their neighboring industrialized and urbanized towns with power consumption which is greater than the mean consumption of the cities of the MRPV. On the other hand, the highest rates of illiteracy of over 10\% are related to cities with a lower level of urbanization and industrialization, typically in commercial and service activities associated with rural work.

It was is also observed that electric energy intensity (mainly when associated with electricity consumption) has a certain degree of influence on the characteristics associated to extreme poverty, such as low per capita income collection and treatment of sewage and solid waste, as well as access to clean water. Therefore, the higher the electricity consumption of the city is, the greater the availability of these services becomes; the existence of discrepancies signals that some less affluent towns are still precarious in providing essential services, such as water supply and sewage.

The per capita income expected by cities is still very well related to the wealth produced by cities and to the consumption of electricity. The occurrence of cities like Cunha, Arapeí and Areias, suggests the existence of sharp socio-economic inequalities in the cities of the MRPV because it is usually observed a low per capita income (less than half the minimum wage) and are inferior extremes considered as discrepant among the cities of the MRPV, i.e. values that are very below the expected.

Table 6 presents the consolidation of 17 factors that better represent the 86 variables inserted in the factor analysis. In terms of the results obtained with the factor analysis, these are some evidence that is aimed at reaching the MDGs. The highlighting reference is the constant presence of women as a key element in the design of the aspects related to the MDGs, even though they are still heavily subjected to precarious living conditions, deficient models of income distribution, low consumption of electricity and precarious health, water supply and sanitation services.

Factor 1 should be highlighted as the most closely correlated factor with the initial analysis variables. This factor reveals a strong relationship between the income produced by the cities of the MRPV before a high urban density scenario, as well as a sharp electric energy consumption (if compared with the average of the cities in the region, mainly in hub cities and their more industrialized and urbanized neighboring towns) for sectors of the economy such as the industrial, commercial and public services, and housing sectors.

However, it is observed the fact that the number of people served by basic health units (UBS, in Portuguese abbreviation) is considered preposterous in typically rural cities, mainly in those around the MRPV. These cities belong to a scenario of pressure for urbanization in search for better basic living conditions; thus, these cities belong (or not) to a pattern of urbanization of cities based on the unbridled industrialization associated with better basic customer service, e.g. health services. The inverse relationship highlights the need for basic care in small towns in the region, even though it does not reflect in a greater degree of urbanization. Furthermore, it is also highlighted that historical and cultural aspects must be kept, since the basic living conditions such as access to potable water, sanitation, electricity, health and income are met to a minimum degree to promote full human dignity.

The second most highly correlated factor shows that some areas of government have high HDI values and adequate sanitation, but it is not always suggested to all citizens of cities, which characterizes distinctions within cities. This occurs not only within cities, but also between the areas of government. The factor directs the understanding that the high per capita consumption of electricity in residential and commercial sectors does not reflect in better indicators for the universalization of basic education, with high rates of illiteracy in less urbanized cities, as well as towards high social vulnerability, extreme poverty and low per capita consumption of electricity in the rural sector.

The relationships highlighted in factor 3 , for example, consider the perception among citizens living on a low HDI. Elderly people living in accentuated social vulnerability, pointing out to the need for greater attention of decision makers in attending this stratum of the population who are exposed to precarious basic services and low per-capita income, characterize this factor.

Factors 4,5 and 6 indicate the wealthiest cities, with citizens of no social vulnerability conditions on the one hand, and on the other one, aspects of land occupation and insertion of women in the labor market (even in rural jobs and wages lower than those of men) making them providers of their families. Such conditions contributes to a reduction of indicators, such as infant mortality, because these women start interacting with more favorable areas of basic human life condition, and the life expectancy of their children is increased because, for example, they have health services, drinking water and sanitation services. Moreover, women start realizing the idea of greater equality of opportunities between the sexes when they have opportunities to work in industrial, commercial and service sectors, which make the homemaker profile characteristic only in the most rural towns in the region.

The existing social vulnerability in the rural sector, with low electric power consumption, when compared to other sectors such as the industrial and commercial ones, is evidenced in factor 7. With a strong correlation existing between water supply, sanitation and garbage collection, factor 8 suggest the need for attending the three elements, aimed at the eradication of diseases during childhood, which cause many infant deaths. This service must also attend the less affluent populations, even if you do not choose urbanization patterns characteristic of hub cities in the MRPV.

\section{Conclusions}

The flow of resources, as a crucial element to the design of the MDGs in cities, government areas or in the whole of the MRPV, is required both in cities and in government areas. The strong degree of influence between the desires of cities in meeting the aspirations of people for better living conditions associated with the consumption of power within the MRPV is strongly highlighted. Whichever the flow direction is between government areas, towns and, especially, among the resident population in the cities, a strong process of urbanization characterizes it.

The selected factors sought to understand the likely gaps and opportunities for municipal governments towards the achievement of the MDGs. Possible actions for this are the improvement of health services, greater attendance of women and their children, attention to the supply of drinking water (for both individual consumption for cooking and basic hygiene) and the collection and treatment of sewerage in order to minimize the spread of diseases caused by lack of basic hygiene.

Another issue pointed out by the analysis is with respect to problems associated with illiteracy, which contribute directly or indirectly to environmental degradation, the spread of diseases and epidemics, infant mortality, by its accentuated degree of difficulty in understanding minimum actions to be taken to reduce these environmental problems.

The contribution of the use of electric energy to the development of positive actions towards the MDGs becomes clearer when it is associated with the provision of benefits to less favored populations, or by historical choices, or cultural elements. The flow of resources, discussed solely by the power consumption, should 
approach energy use awareness and not just the supply of industries.

The data and resources brought up and extracted by the cities that make up the MRPV generate opportunities for expansion of conducive actions to environmental preservation. The conscious use of other renewable sources of electricity generation, and not just those coming from hydroelectric plants, as well as recycling, changing consumption habits, especially in cities with a high level of urbanization, and in cities or regions that use the same paths to economic development, are examples of such actions.

The autonomy suggested to women greatly contributes to the design of new goals, which is auxiliary to the MDGs. Despite the economic gains of cities are not favored in any meaningful way by the insertion of women as decision elements in their residences as income providers for their families, it will already be reflected on the improvement of social and environmental goals. Due to this, reducing the proliferation of diseases, the reduction of extreme poverty, the eradication of hunger, greater equality between the sexes, the reduction of social vulnerabilities affecting elderly people with better health services, leisure and social insertion are observed as a consequence of this fact.

\section{Acknowledgments}

The following sponsoring agencies are acknowledged: the Brazilian National Council for Scientific and Technological Development $(\mathrm{CNPq})$ for the productivity grant of one of the authors (Process 302939/2011-3); the São Paulo State Research Foundation (FAPESP) for the Regular Research Award (Process 2013/07287-3); the Foundation for the Development of UNESP (FUNDUNESP) for the Regular Research Award (Process 1908/009/13-PROPe/CDC).

\section{References}

[1] UN-United Nations. Human development report 2013. New York, United States. Available in $\langle$ http://hdr.undp.org $; 2013$ [last accessed 25.06.14].

[2] Dahiya B. Cities in Asia, 2012: demographics, economics, poverty, environment and governance. Cities 2012;29:S44-61.

[3] UN-Habitat. State of Latin American and Caribbean cities 2012: towards a new urban transition. Kenia. Avaliable In: /www.citiesalliance.org/sites/citiesal liance.org/files/SOLAC-ProjectOutput.pdf); 2012 [last accessed 25.06.14].

[4] UN-Habitat. The state of Asian cities 2010/11, vol. 1. Available in: 〈www fukuoka.unhabitat.org $; 2010$ [last accessed 01.09.14].

[5] UN-Habitat. Gender equality for a better urban future: an overview of UNHabitat's gender equality action plan (2008-2013). Available in: 〈www fukuoka.unhabitat.org); 2013 [last accessed 12.06.14].

[6] Hogan DJ. Parte I À busca de caminhos - População e Meio Ambiente: a emergência de um novo campo de estudos. Dinâmica Popul. e mudança Ambient. cenários para o Desenvolv. Bras., Campinas, Brasil: NEPO/UNICAMP Núcleo de Estudos de População; 2007, p. 240.

[7] UN-United Nations. United Nations millenium declaration. Gen Assem. Available in: 〈www.un.org/millennium/declaration/ares552e.htm〉; 2000. p. 9 [last accessed 11.01.13].

[8] Cowell FA. Measuring inequality. 3 edition (February 4, 2011). USA: Oxford University Press; 2009.

[9] Litchfield JA. Inequality: methods and tools. World Bank, Worldbank; 1999.

[10] Goldemberg J. Energia, Meio Ambiente \& Desenvolvimento. 2nd ed. São PauloSP, Brasil: EDUSP-CESP; 2001.

[11] Goldemberg J. Development and energy, overview. Encycl Energy 2004; 1:801-7.

[12] Arribas-Bel D, Kourtit K, Nijkamp P. Benchmarking of world cities through self-organizing maps. Cities 2013;31:248-57.

[13] Klasen S. Economic growth and poverty reduction: measurement issues using income and non-income indicators. World Dev 2008;36:420-45.
[14] Guimarães RP. Modernidad, medio ambiente y etica: un nuevo paradigma de desarollo. Ecol. Política Nat. Soc. e Utopía, Buenos Aires: CLACSO - Consejo Latinoamericano de Ciencias Sociales; 1997. p. 53-82.

[15] UN-United Nations. We can end poverty. Available in: 〈http://www.un.org/ millenniumgoals/poverty.shtml ; 2013 [last accessed 01.08.13]

[16] Worldbank. Poverty overview. Available In: 〈http://www.worldbank.org/en/ topic/poverty/overview $\rangle ; 2014$ [last accessed 01.09.14].

[17] Pritchett L, Kenny C. Ideals : the risks of defining development down working paper 338; August 2013.

[18] IPEA. IPEA Instituto de Pesquisa Econômica Aplicada. Available In: 〈www. ipeadata.gov.br $>$; 2014 [last accessed 10.10.14].

[19] IBGE. Pesquisa de orçamentos familiares 2008-2009: despesas, rendimentos e condições de vida. Rio de Janeiro; 2010.

[20] Deichmann U. Geographic aspects of inequality and poverty. World Bank; 1999. p. 1-13.

[21] Abel W. Scientific American magazine. Metab Cities 1965;213(3):156-74.

[22] Newman PWG. Sustainability and cities: extending the metabolism model. Landsc Urban Plan 1999;44:219-26.

[23] Deàk C. A cidade: do burgo à metrópole. Espaço Debates 1991;34:113-20.

[24] Milder J. Sustainable urban form. In: van Bueren Ellen, van Bohemen Hein, Itard Laure, Visscher H, editors. Sustainable urban environments: an ecosystem approach; 2012. p. 263-84.

[25] Modi VS, McDade S, Lallament D, Saghir J. Energy services for the millennium development goals. New York, USA; 2005.

[26] Parajuli R. Access to energy in Mid/Far west region-Nepal from the perspective of energy poverty. Renew Energy 2011;36:2299-304.

[27] Bhide A, Monroy CR. Energy poverty: a special focus on energy poverty in India and renewable energy technologies. Renew Sustain Energy Rev 2011;15:1057-66.

[28] Coelho ST, Goldemberg J. Energy access: lessons learned in Brazil and perspectives for replication in other developing countries. Energy Policy 2013;61:1088-96.

[29] Martchamadol J, Kumar S. An aggregated energy security performance indicator. Appl Energy 2013:103:653-70.

[30] Charpentier JP. Toward a better understanding of energy consumption-I. The distribution of per capita energy consumption in the world. Energy 1976:325-34.

[31] Nussbaumer P, Bazilian M, Patt A. A statistical analysis of the link between energy and the millennium development goals. Clim Dev 2013:37-41.

[32] SEADE. Fundação Sistema Estadual de Análise de Dados. Informações Dos Municípios Paul Available In:〈www.seade.sp.gov.br〉; 2014 [last accessed 01.09.14].

[33] IBGE. Estatísticas das cidades brasileiras. Available in: 〈www.ibge.gov.br $\rangle ; 2014$ [last accessed 01.09.14].

[34] UN-Water. Water and urbanisation. UN-WATER. Available In: 〈www.unwater. org ; 2010. p. 1-4 [last accessed 11.03.13].

[35] UN-Unifem. UNIFEM. United Nations development fund for women. Available in: 〈www.unwomen.org ; 2013 [last accessed 03.07.13].

[36] BRASIL. Objetivo de Desevolvimento do Milênio-Brasil. Available in: 〈www. odmbrasil.gov.br $>2013$ [last accessed 01.10.14].

[37] BRASIL. Aneel-Agência Nacional de Energia Elétrica. Available in: 〈www.aneel, gov.br>; 2014 [last accessed 01.10.14].

[38] BRASIL. ANP-Agência Nacional de Petróleo, Gás Natural e Biocombustíveis. Available in: 〈Www.anp.gov.br〉; 2013 [last accessed 15.10.14].

[39] BRASIL. EPE. Empresa de Pesquisa Energética. Plano Decenal de Expansão de Energia 2021. Brasília-DF, Brasil: Ministério de Minas e Energia. Available In: 〈www.epe.gov.br〉; 2012 [last accessed 15.10.14]

[40] BRASIL. Municipalização dos ODM e participação social. Brasília-DF, Brasil: Secretaria Geral; 2009 Available in: 〈www.secretariageral.gov.br/.arquivos/ arquivos-novos/arquivos-novos-2011/MunicipalizacaodosODM.pdf ; 2009 [last accessed 02.06.14].

[41] UN-United Nations. Indicators of sustainable development: guidelines and methodologies, 3rd ed. New York, USA. Available In: 〈www.un.org/esa/sus tdev/natlinfo/indicators/guidelines.pdf ; 2007 [last accessed 03.07.14].

[42] Perobelli FS, De Oliveira CCC. Energy development potential: an analysis of Brazil. Energy Policy 2013;59:683-701.

[43] Mingoti SA. Análise de dados através de métodos de estatística multivariada: Uma abordagem aplicada. Editora UFMG; 2005.

[44] Sewell M. Factor analysis, vol. 2007. London; 2008.

[45] Mingoti SA. Análise de dados através de métodos de estatística multivariada: Uma abordagem aplicada. Editora UFMG 2005.

[46] Anderson TW. An introduction to multivariate statistical analysis. 3rd ed.. New Jersey: Wiley-Interscience; 2003.

[47] Morrison DF. Multivariate statistical methods. 3rd ed.. Philadelphia (USA): University of Pennsylvania; 2005.

[48] IBM. IBM SPSS - Statistical package for social science; 2013.

[49] Charpentier JP, Beaujean JM. Toward a better understanding energy consumption-II - factor analysis: a new approach to energy demand. Energy 1976:413-28 